\title{
Florida State University Libraries
}

Electronic Theses, Treatises and Dissertations

The Graduate School

2006

Alone but Feeling No Pain: Effects of Social Exclusion on Physical Pain Tolerance and Pain Threshold, Affective Forecasting, and Interpersonal Empathy

C. Nathan Dewall 


\title{
THE FLORIDA STATE UNIVERSITY \\ COLLEGE OF ARTS AND SCIENCES
}

\section{ALONE BUT FEELING NO PAIN: EFFECTS OF SOCIAL EXCLUSION ON PHYSICAL \\ PAIN TOLERANCE AND PAIN THRESHOLD, AFFECTIVE FORECASTING, AND \\ INTERPERSONAL EMPATHY}

By

\author{
C. Nathan DeWall \\ A thesis submitted to the \\ Department of Psychology \\ in partial fulfillment of the \\ requirements for the degree of \\ Master of Science
}

Degree Awarded:

Spring Semester, 2006 
The members of the Committee approve the thesis of C. Nathan DeWall, defended on February $18,2005$.

Roy F. Baumeister

Professor Directing Thesis

Thomas Joiner

Outside Committee Member

Jon K. Maner

Committee Member

The Office of Graduate Studies has verified and approved the above named committee members. 


\section{TABLE OF CONTENTS}

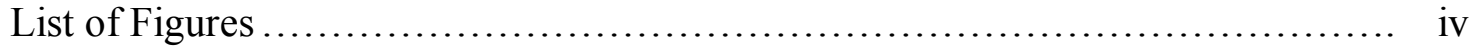

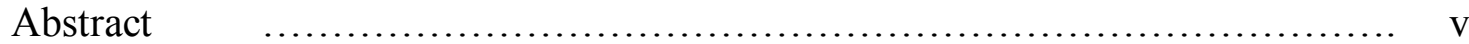

ALONE BUT FEELING NO PAIN: EFFECTS OF SOCIAL EXCLUSION ON

PHYSICAL PAIN TOLERANCE AND PAIN THRESHOLD, AFFECTIVE

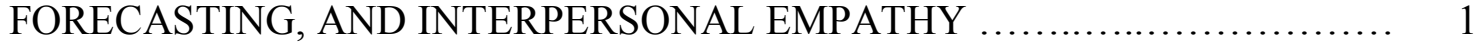

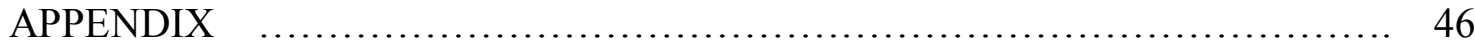

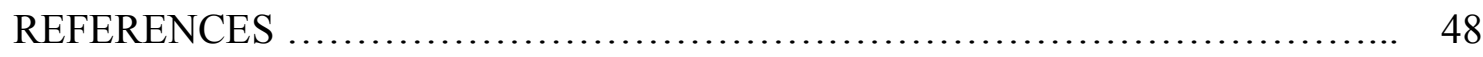

BIOGRAPHICAL SKETCH............................................. 54 


\section{LIST OF FIGURES}

Figure 1. Proposed mediational model of social exclusion, numbness to physical pain, and emotional insensitivity

page 43

Figure 2. Mediational effect of increased pain threshold on social exclusion and decreased empathy. Experiment 4

Figure 3. Mediational effect of increased pain tolerance on social exclusion and decreased empathy. Experiment 4

page 45 


\begin{abstract}
Prior findings of emotional numbness (rather than distress) among socially excluded persons led us to investigate whether exclusion causes a far-reaching insensitivity to both physical and emotional pain. Experiments 1-4 showed that receiving an ostensibly diagnostic forecast of a lonesome future life reduced sensitivity to physical pain, as indicated by both (higher) thresholds and tolerance. Exclusion also caused emotional insensitivity, as indicated by reductions in affective forecasting of joy or woe over a future football outcome (Experiment 3), as well as lesser empathizing with another person's suffering from either romantic breakup (Experiment 4) or a broken leg (Experiment 5). Mediation analyses confirmed the link between insensitivities to physical and emotional pain.
\end{abstract}




\section{ALONE BUT FEELING NO PAIN: EFFECTS OF SOCIAL EXCLUSION ON PHYSICAL PAIN TOLERANCE AND PAIN THRESHOLD, AFFECTIVE FORECASTING, AND INTERPERSONAL EMPATHY}

People depend heavily on others for much of their physical and mental well-being. With no fangs, no claws, an extremely prolonged childhood phase of dependency and vulnerability, and other physical weaknesses, human beings are not well suited to living in isolation from others. Given the importance of acquiring and maintaining membership in social groups, it is therefore hardly surprising that people would react strongly to any threat of social exclusion. Multiple laboratory studies of social exclusion have found, however, that people respond to social exclusion in a relatively detached and emotionally numb manner. Socially excluded people often report emotional states that do not differ significantly from participants who experience social acceptance or control participants (Baumeister, Twenge, \& Nuss, 2002; Gardner, Pickett, \& Brewer, 2000; Twenge, Baumeister, Tice, \& Stucke, 2001; Twenge \& Campbell, 2003; Twenge, Catanese, \& Baumeister, 2002; Zadro, Williams, \& Richardson, 2004). Thus, psychologists are confronted with a paradox as to why people respond to a significant event such as social exclusion with emotional numbness and detachment.

The first purpose of the current investigation was to resolve the paradox as to why rejected people report emotional numbness by identifying a possible mechanism by which people respond to social exclusion. Social exclusion poses a serious threat to a person's physical and psychological well-being, as indicated by higher rates of physical and mental illnesses among people who live alone as compared with people who have strong social networks (Argyle, 1987; Cacioppo, Hawkley, \& Berntson, 2003; Kiecolt-Glaser, Ricker, George et al., 1984; Lynch, 1979; Myers, 1992). These findings confirm that social exclusion has potentially drastic and negative effects on physical and psychological health, but they offer no explanation for the finding that people respond to social exclusion with emotional numbness (e.g., Twenge et al., 2001).

The view proposed in the current paper is that certain interpersonal events, such as social rejection, activate the body's pain response system and potentially alter how it registers physical and emotional pain. With regard to physical pain, social exclusion may disrupt the ability to respond to physical pain in the same manner as people who have not experienced social exclusion. This would lead to increases in both pain threshold (i.e., sensitivity to pain) and pain 
tolerance (i.e., withstanding greater pain). Hence the first goal of this research (tested in Experiments 1-4) was to demonstrate that socially excluded people may become more numb to physical pain. The second goal of this work was to extend the idea of physical numbness to emotional functioning. If the body uses the same system to respond to physical injury and interpersonal injury, then physical pain and interpersonal emotions may be linked — and just as the body goes numb to pain, it may become less sensitive to emotion. If the emotional system ceases to function properly in the aftermath of social exclusion, people might show abnormalities not only in their emotional reactions to current events but also in their forecasts of emotional responses to future events. They might also lose their empathy and sympathy for the physical suffering of another person. Last, and ironically, rejected people might even lose their empathy for the suffering of someone else who has also suffered rejection. Experiments 3-5 tested these predictions.

Social Exclusion and Emotional Responding: The Paradox of Detachment and Numbness

A desire to form and maintain social bonds with others is a fundamental and pervasive desire among humans (Baumeister \& Leary, 1995). Insofar as belongingness is a basic need rather than a want, people experience considerable difficulties when their need to belong is unsatisfied or frustrated. A lack of stable relationships also has detrimental effects on one's health (Cacioppo, Hawkely, \& Berntson, 2003; Hawkley, Burleson, Berntson, \& Cacioppo, 2003; Lynch, 1979; see Uchino, Cacioppo, \& Kiecolt-Glaser, 1996, for a review). Thus, social exclusion has a profound negative impact on psychological functioning and physical health.

One might assume and hope that excluded people would show adaptive responses of changing themselves so as to become more socially attractive or to take better care of themselves as individuals. Perhaps surprisingly, the opposite is often found. Rejected people exhibit decreased intellectual functioning (Baumeister et al., 2002), become more aggressive toward others (Buckley et al., 2004; Twenge et al., 2001; Twenge \& Campbell, 2003), are less willing to self-regulate (Baumeister, DeWall, Ciarocco, \& Twenge, in press), and engage in various selfdefeating behaviors such as risk-taking and procrastination (Twenge et al., 2002). None of these seems likely to foster interpersonal acceptance or personal health and well-being,

Social exclusion has destructive effects on health and behavior, but people often respond to exclusion with emotional numbness and detachment. Socially excluded participants frequently report emotional states that do not differ significantly from socially accepted and control 
participants (Gardner et al., 2000; Twenge et al., 2002; Baumeister et al., 2002; Zadro et al., 2004). When differences in emotion are found, these differences do not mediate the behavioral consequences of social exclusion. Even researchers who typically find that social exclusion leads to emotional distress have not found that emotional distress mediates the behavioral consequences of social exclusion (Buckley et al., 2004; Williams et al., 2000). Given the fundamental nature of the need to belong, one might reasonably expect that real, potential, or imagined social exclusion would result in severe emotional reactions. It is therefore unclear why emotion plays such a minor role in explaining behavioral responses to social exclusion.

Researchers have recently begun to explore the possible reasons behind the apparent absence of emotional response to social exclusion. Twenge et al. (2003) proposed that one reason socially excluded people report feelings of inner numbness is that exclusion leads to a defensive state of cognitive deconstruction. The deconstructed state has been used previously to describe presuicidal tendencies (Baumeister, 1990), and it is marked by emotional numbness, an altered perception of time, thoughts of meaninglessness, lethargy, and avoidance of self-focused attention. Twenge et al. (2003) showed that socially excluded people exhibited each of these symptoms of cognitive deconstruction. Social exclusion leads to behaviors that could preclude the possibility of gaining future acceptance (e.g., aggression, self-defeating behavior), but the deconstructed state may offer rejected people a temporary reprieve from feeling the intense pain or distress that can accompany threats to belongingness. Although escaping from aversive emotional states and high self-awareness may be beneficial in the short term, such behaviors are characteristic of severe psychopathology in clinical populations (Bancroft, Skrimshire, \& Simkins, 1976; Bromberg \& Sehilder, 1936; Hawton, Cole, O'Grady, \& Osborn, 1982; Parker, 1981; Smith \& Bloom, 1985) and of a variety of self-destructive behaviors in non-clinical samples (see Baumeister \& Scher, 1988, for a review). The experiments reported in this paper sought to identify the physical and psychological consequences that follow from social exclusion.

If people have normal or natural defenses that help them escape or minimize emotional distress, then social exclusion may temporarily impair the ability to experience emotions in a normal fashion. The theory proposed in the current paper is that the emotion system temporarily shuts down in response to social exclusion. This view is an extension to the deconstructed state theory proposed by Twenge et al. (2003) and focuses specifically on the tendency for people to 
report emotional numbness in the immediate aftermath of social exclusion. If social exclusion temporarily saps the capacity for the emotion system to function properly, socially excluded people may respond differently to physically distressing events, such as physical pain. This would be shown by decreased sensitivity to pain and an increased willingness or ability to endure painful stimuli for extensive periods of time. The following section reviews evidence regarding the relationship between social exclusion and physical pain.

\section{Social and Physical Pain}

There is reason to believe that the pain of social exclusion shares many of the same neural and psychological mechanisms as experiences of physical pain. At a purely linguistic level, people frequently use words connoting physical pain when describing emotional responses to distressing events. For example, people may report feeling "hurt" or "crushed" following the dissolution of a meaningful relationship (Leary \& Springer, 2000). MacDonald and Leary (2005) have suggested that the similarity between descriptions of social and physical pain extends beyond mere metaphor. Specifically, they proposed that social pain and physical pain operate via shared physiological mechanisms, including the anterior cingulate cortex, periaqueductal gray brain structures, and the opioid and oxytocin neuroendocrine systems (see also Rossi, Pasternak, \& Bodnar, 1993).

Decades ago, Panksepp and colleagues proposed a link between social and physical pain (Herman \& Panksepp, 1978; Panksepp, Herman, Conner, Bishop, \& Scott, 1978; Panksepp, Vilberg, Bean, Coy, \& Kastin, 1978). They suggested that as evolution prepared animals for increasing social interaction, instead of creating entirely new systems to react to social events such as being rejected or excluded, it piggy-backed these responses onto the existing systems that were hard-wired for responding to physical pain. Social events might therefore activate the body's pain response system and potentially alter how it would register physical pain.

Recent neuroscience and $\mathrm{AMRI}$ research has shown that the anterior cingulate cortex (ACC) functions as a neural "alarm" system to warn people that factors in their environment threaten their goals (Eisenberger, Lieberman, \& Williams, 2003; Eisenberger \& Lieberman, 2004; Nelson \& Panksepp, 1998; Bush, Luu, \& Posner, 2000; Kimbrell, George, Parekh, et al., 1999). Eisenberger et al. (2003) showed that the ACC plays a prominent role in the detection of threats to belongingness. In their fMRI study, ostracized people showed activation of the dorsal ACC. Ostracized people also showed activation of the right ventral prefrontal cortex (RVPFC), 
which has been previously linked to the regulation of physical pain distress and negative affect (Petrovic, Kalso, Petersson, \& Ingvar, 2002; Hariri, Bookheimer, \& Mazziotta, 2000). Thus, preliminary evidence suggests that Panksepp and colleagues were correct in proposing that certain physiological processes responsible for detection and regulation of physical pain were coopted to sense and respond to emotionally painful events, such as being rejected or excluded.

Additional research has shown that the periaqueductal grey (PAG) brain structures, which receive input from the body's injury detection system (nociceptive system) and ACC, are involved in the detection of physical pain and are implicated in animal bonding behavior (Craig \& Dostrovsky, 1999). Panksepp (1998) demonstrated that activation of the PAG elicited separation distress cries from rats, and further evidence showed that lesions to the PAG led to reduced separation distress cries (Wiedenmayer, Goodwin, \& Barr, 2000). Administration of the neuropeptide oxytocin and opioids such as morphine have also been shown to reduce separation distress cries in rats (Carden, Hernandez, \& Hofer, 1996; Carden \& Hofer, 1990; Insel \& Winslow, 1991). These findings indicate that some physiological systems respond to both physical pain and socially distressing events.

Most relevant to the current investigation, however, is evidence that separation from caregivers and isolation from conspecifics results in decreased sensitivity to physical pain, or analgesia. Several studies have shown that short-term isolation produces reduced pain sensitivity in rat pups (Kehoe \& Blass, 1986a, 1986b; Naranjo \& Fuentes, 1985; Spear, Enters, Aswad, \& Louzan, 1985), mice (Konecka \& Sroczynska, 1990), cows (Rushen, Boissy, Terlouw, \& de Passillé, 1999), and chicks (Sufka \& Hughes, 1990; Sufka \& Weed, 1994; see MacDonald \& Leary, 2005, for a review). Thus, threats to belongingness appear to activate neural mechanisms associated with physical pain and the regulation of pain in some non-human species (Nelson \& Panksepp, 1998; Panksepp, 1998).

Previous research has shown that social and physical pain share common physiological mechanisms in some animals, but research has not provided much evidence about whether a similar link exists in humans. MacDonald, Kingsbury, and Shaw (in press) showed that people high in rejection sensitivity responded to ostracism with decreased sensitivity to physical pain (pain threshold) on the cold-pressor task, but people low in rejection sensitivity did not show the same pattern of responding. If threats to belongingness activate basic neural mechanisms designed to regulate pain (Eisenberger et al., 2003), one would expect all ostracized participants 
to exhibit decreased sensitivity to physical pain. Those preliminary findings were also mute about another important issue, namely what effects increased pain threshold and tolerance may have for emotional responding, to which we turn in the next section.

\section{Effects of Increased Pain Threshold and Pain Tolerance for Emotional Responding}

If people respond to social exclusion with a subdued emotional response, what processes might lead excluded people to report relative emotional numbness and detachment? One possible answer is that people respond to social exclusion by becoming physically numb to pain, which in turn would lead to relative emotional numbness. This shutdown of the emotion system might be beneficial in terms of immediately reducing a person's suffering, in the same way that physical injuries often create an analgesia that saves him or her from feeling acute, ongoing pain for as long as the injury lasts. If this is true, exclusion should influence how people respond to physically painful stimuli, which in turn would influence how people respond to various emotional events. Specifically, excluded people should become numb to physical pain, and this physical numbness should lead to emotional insensitivity (see Figure 1).

What would provide the best measures of emotional insensitivity? One method would be direct self-reports of emotion, which (sure enough) tend to indicate no emotional reaction (e.g., Baumeister et al., in press). Self-reported emotion may not provide the best measure, however, because of social desirability biases and other factors that could influence responding. For example, excluded people might feel emotionally upset but refuse to admit it. To avoid these methodological pitfalls of direct self-reports of emotion, we measured two emotional phenomena in which people seemingly rely on their current state and emotional simulation (imagining how oneself would feel) to make judgments about events distant from the present. The first of these phenomena is affective forecasting; the other is empathy for another's suffering. If rejected people are full of emotion but reluctant to admit their distress out of self-presentation concerns, they should be quite willing to predict strong future emotional reactions and to empathize and sympathize with others' suffering. But if their emotional systems have really shut down, excluded people should find it difficult to imagine having strong emotions in response to hypothetical future events, and they likewise might not empathize with another person's distress.

In a large research program, several researchers have examined the ways in which people predict their future feelings, a process referred to as affective forecasting (see Wilson \& Gilbert, 2003, for a review). This program of research has shown consistently that people overestimate 
the duration and intensity of their emotional responses to future events. People overestimate how happy they will be after winning a date on a simulated dating game (Wilson, Wheatley, Kurtz, Dunn, \& Gilbert, 2004), predict greater distress following a romantic breakup or denial for academic tenure than actually occurs (Gilbert, Pinel, Wilson, Blumberg, \& Wheatley, 1998), and overrate what their quality of life will be if they receive an important medical procedure (Jepson, Loewenstein, \& Ubel, 2001). Other research has shown that a person's current emotional state can bias his or her predictions of future emotional responses and other decision-making processes (Gilbert, Gill, \& Wilson, 2002; Loewenstein, O’Donoghue, \& Rabin, in press; Nelson \& Morrison, in press; Van Boven \& Loewenstein, 2003).

If social exclusion hampers the capacity for people to respond to their own emotions, rejected people might show a different pattern of affective forecasting than other participants. Specifically, rejected participants might report less happiness when forecasting their emotional reaction to a positive event, and greater happiness when forecasting their emotional reaction to a negative event. In contrast, socially accepted and control participants show exhibit the previously documented overestimation of their happiness or sadness to future events. If physical numbness to pain is the mechanism that leads to emotional numbness, the tendency for rejected participants to become physically numb to pain should mediate the relationship between social exclusion and forecasts of an affectively numb future.

Another process that may illustrate the relationship between social exclusion and emotional responding is the ability of rejected people to show empathy and sympathy toward people in various forms of physical and psychological distress. Previous research has shown that rejected people tend to behave less prosocially than non-rejected people (Twenge et al., 2005), and work by Batson and colleagues has demonstrated that empathy plays a prominent role in shaping prosocial behavior (Batson, Klein, Highberger, \& Shaw, 1995). It seems therefore plausible that rejected participants might become less able to feel empathy toward another person's suffering. If physical numbness to pain is the mechanism by which rejected people become emotionally insensitive, physical numbness to painful stimuli should mediate the relationship between rejection and lack of empathic responding.

\section{Present Research}

The present experiments tested the theory that social exclusion activates the body's pain system and sets of responses that may reduce sensitivity to both physical and emotional 
suffering. Our prediction had two parts. First, participants who experienced social exclusion would show increased pain threshold and pain tolerance compared to socially accepted and control participants. Next, increased threshold and tolerance to physical pain should lead to emotional insensitivity. Participants who experience social exclusion should find it difficult to predict strong emotional responses to hypothetical future events, and should exhibit decreased empathy and sympathy to others' suffering compared to participants who do not experience rejection. Moreover, these symptoms of emotional shutdown should be mediated by increased pain threshold and pain tolerance among socially excluded participants.

To provide converging evidence and rule out alternative manipulations, multiple methods and measures were used. Two manipulations of social exclusion were used in the current investigation. In the first procedure (Experiments 1-4), participants completed a personality test and received feedback that they would have a lonely future (Future Alone), wonderful relationships (Future Alone), or a future marked by frequent accidents (Misfortune Control). Other participants received no feedback on their personality test (No feedback control). The second procedure (Experiment 5) used an imagination/thought-listing manipulation of social exclusion. Participants wrote about a time when they felt excluded or rejected from others (rejection condition) versus a time when they felt accepted by others (acceptance condition). A group of control participants wrote about something they did the day before they were in the study. Research has shown that real and imagined events activate many of the same neural and psychological processes (Kosslyn, Pascual-Leone, Felician, et al., 1999; McGuire, Shah, \& Murray, 1993), and so it was predicted that both rejection manipulations would lead to physical and emotional numbness.

To test whether the emotion system temporarily ceases functioning normally following social exclusion, affective forecasting and empathy were measured. Affective forecasting was measured by having participants predict how happy or sad they would be if their college football team won or lost an upcoming game against their rival school (Experiment 3). Empathy was measured by having participants report to what degree they felt empathy-related emotions (e.g., compassionate, warmth, softhearted) they felt toward a person who had recently experienced the dissolution of a romantic relationship (Experiment 4) or a recent physical injury (Experiment 5). Emotional response was also measured in all studies using various self-report measures.

Thus, the current investigation sought to resolve the seeming paradox as to why people 
respond to such a threatening experience as rejection with emotional numbness. The first goal was to test the hypothesis that people become numb to physical pain in the aftermath of social exclusion. The second goal of this work was to demonstrate that physical numbness has consequences for other forms of emotional responding, such as affective forecasting and interpersonal empathy.

\section{Experiment 1: Not Feeling My Own Pain}

The purpose of Experiment 1 was to test the hypothesis that social exclusion reduces sensitivity to pain. Social exclusion was manipulated by having participants complete a personality test and giving some participants bogus feedback stating that their personality profile enabled the researchers to predict that they would most likely end up alone in life. This Future Alone condition has been used in past research to create a sense of social exclusion and impending isolation, because people take it to mean that something about their personalities will cause others to reject them (Twenge et al., 2001). There were also two control groups. One of these groups received personality feedback stating that they had a personality type that would lead to a future filled with several meaningful and lasting relationships (Future Belonging). The other control group was given no feedback regarding their personality or the implications their personality may have for their future belongingness status.

Two measures of physical pain sensitivity, namely pain tolerance and pain threshold, were measured using a pressure algometer (Type II, Somedic Inc., Solletuna, Sweden). Pressure algometers measure pain threshold and pain tolerance by exerting pressure onto the skin of the participant, usually on the index finger of the dominant hand (Chesterton, Barlas, Foster, Baxter, Wright, 2003; Kosek \& Lundberg, 2003; Polianskis, Graven-Nielsen, Arendt-Nielsen, 2001; Schreiber, Shmueli, Grunhaus, Dolberg, Feldinger, Magora, Shapira, 2003). Pain threshold and pain tolerance were measured by having participants verbally report when they perceived a change in pressure pain (pain threshold) and when they felt they could no longer tolerate the pressure pain (pain tolerance). Baseline pain tolerance and pain threshold measurements were taken at the beginning of the experiment and post-experimental measurements were taken after participants were exposed to the social exclusion manipulation. This procedure had two main benefits. First, it allowed us to control for individual differences in pain tolerance and pain threshold by covarying baseline scores with post-feedback scores. Second, it enabled us to compute difference scores by subtracting baseline scores from post-feedback scores. 
We predicted that participants in the Future Alone condition would have higher pain thresholds and higher pain tolerance than participants in the two control conditions. We thought this mixture of procedures posed an especially conservative test of our hypothesis, because participants in the Future Alone condition were not actually experiencing a specific rejection by a friend or lover or even by a stranger; they merely received ostensibly diagnostic feedback that in the indeterminate future they would experience aloneness. We hoped, however, that a future diagnostic forecast of social exclusion would be sufficient to alter their sensitivity to pain in the immediate present.

The inclusion of both pain threshold and pain tolerance measures provided two separate chances to confirm or disconfirm our hypothesis that social exclusion leads to numbness to physical pain. We had no a priori reason to think that socially excluded participants would show increases in pain threshold but not in pain tolerance (or vice versa). If socially excluded participants showed increases in both pain threshold and pain tolerance, however, that would provide converging evidence in support of our hypothesis.

\section{Method}

Participants. Thirty-three right-handed undergraduates (24 women) participated in this study in exchange for partial course credit. We restricted participation in the current study to people who were non-smokers and right-handed because smoking has been shown to reduce pain sensitivity (Kanarek, \& Carrington, 2004; Pomerlau, Turk, \& Fertig, 1984), and because left limbs show greater pain sensitivity than right limbs, regardless of hand of preference (Murray \& Hagan, 1973). Participants were also required to not have ingested any sugared foods or alcoholic beverages for at least 8 hours prior to participation in the experiment (Kanarek, \& Carrington, 2004; Mercer \& Holder, 1997). Finally, participants were required not to ingest any analgesics (e.g., aspirin, acetaminophen) or other pain suppressants (e.g., oxycodone with acetaminophen or propoxyphene with acetaminophen) for at least 8 hours prior to participation in the experiment. Prior to participation in the study, participants reported whether they met all of the participation requirements. All participants followed each of these instructions for participation and were included in the final data set. Participants were $67 \%$ White and 33\% racial minority. The average age was 18.6 years.

Materials and procedure. Participants arrived at the lab individually for a study ostensibly concerned with the relation between personality and physical sensitivity. After giving informed 
consent, participants completed measures of rejection sensitivity (Downey \& Feldman, 1996) and global self-esteem (Rosenberg, 1965). Baseline measurements of pain threshold and pain tolerance (two trials each) were then taken using a pressure algometer (Type II, Somedic Inc., Solletun8a, Sweden). For pain threshold, participants were instructed to say "now" when they first felt pain due to the pressure increase. For pain tolerance, participants were instructed to say "stop" when the pain became too uncomfortable to continue. At this point, the experimenter immediately retracted the algometer. The digital display showed the value of pressure applied at the moment the algometer was retracted. The algometer was applied perpendicularly to the skin and lowered at a rate of approximately $5 \mathrm{kPA} / \mathrm{sec}$ until pain threshold or tolerance was reached, as indicated by participants' verbal report. All pain measurements were taken at the first dorsal interosseous muscle (i.e., behind the first knuckle of the index finger) of the participant's dominant hand. The order of the pain tolerance and threshold measurements was counterbalanced across participants. To prevent habituation, there was a $1.5 \mathrm{~min}$ interval between all pain threshold and tolerance measurements (Orbach, Mikulincer, King, Cohen, \& Stein, 1997).

Participants then completed a brief demographic questionnaire and the Eysenck Personality Questionnaire (EPQ; Eysenck \& Eysenck, 1975). To bolster the credibility of the cover story, participants received accurate feedback regarding their extraversion score.

Participants then received bogus feedback about the implications their extraversion score would have for their future belongingness. Following a procedure developed by Twenge et al. (2001), participants were randomly assigned to one of three social feedback conditions: Future Belongingness, Future Alone, and No Feedback control. Based on their extraversion score, Future Belongingness participants were told:

"Scoring high or fairly high in extraversion means that you like people and people like you. Being an extravert is a really good thing for relationships." or

"Being an introvert can be a good thing for relationships. There's been some research showing that introverts have an easier time keeping relationships together. Instead of running around meeting new people all the time, they're good at keeping the relationships they have."

In contrast, Future Alone participants were told:

Scoring high or fairly high in extraversion is a good thing for meeting people, especially when 
you're in college... but there's been some research that's shown that people who score high on extraversion have trouble keeping their relationships stable later in life.

or

Being an introvert is not really a good thing for relationships. Once you get out of college, it's harder to meet people, so it's easier if you score really high on extraversion. If you don't it makes it more difficult to meet people.

Participants assigned to the No feedback control condition were not given any feedback regarding their extraversion score.

The experimenter then read participants a personality description. Participants assigned to the Future Belongingness condition received the following personality description: You're the type who has rewarding relationships throughout life. You're likely to have a long and stable marriage and have friendships that will last into your later years. The odds are that you'll always have friends and people who care about you.

For participants assigned to the Future Alone condition, participants were told:

You're the type who will end up alone later in life. You may have friends and relationships now, but by mid-20s most of these will have drifted away. You may even marry or have several marriages, but these are likely to be short-lived and not continue into your 30s. Relationships don't last, and when you're past the age where people are constantly forming new relationships, the odds are you'll end up being alone more and more.

Participants assigned to the No feedback control group did not receive any feedback regarding their personality type.

Participants then completed the Brief Mood Introspection Scale (BMIS; Mayer \& Gaschke, 1988). After completing the BMIS, measurements of pain threshold and tolerance (five trials each) were taken. When participants had completed the pain threshold and tolerance measurements, they were carefully and thoroughly debriefed. Care was taken to ensure that participants recognized that the feedback they had received was based on random assignment and had nothing to do with them, their personality, or any form they had completed during the experimental session. When the experimenter was certain that participants understood the true purpose of the experiment, participants were given partial course credit, were thanked for their 
time, and were dismissed.

\section{Results}

We computed both the omnibus $F$ statistic and performed linear contrasts comparing socially excluded participants (i.e., Future Alone) with non-socially excluded participants (i.e., Future Belongingness and No feedback control). Pain threshold and tolerance scores were analyzed in two main ways. First, post-feedback pain threshold and pain tolerance scores were compared using baseline pain threshold and pain tolerance scores as a covariate. Second, a difference score was computed by subtracting baseline threshold and tolerance scores from postfeedback scores. There were no main effects or interactions on pain threshold and tolerance (or any other dependent measure) involving participant gender or ethnicity in this or any other of the studies reported in this paper. Hence, these variables will not be discussed further.

\section{Pain Threshold}

As predicted, socially excluded participants showed significantly higher pain thresholds than participants who were led to anticipate a future filled with social acceptance or who received no personality feedback. Results from ANCOVA on pain threshold scores indicated that there was significant variation between the three experimental groups, $F(2,30)=17.85, p<.001$. A 2 -1 -1 linear contrast confirmed that Future Alone participants had higher pain thresholds compared to Future Belongingness and No feedback control participants, $F(1,30)=33.63, p<$ .001. Pairwise comparisons using the ANCOVA mean square error revealed that Future Alone participants had higher pain thresholds than Future Belonging participants, $F(1,30)=33.33, p<$ $.001, d=1.47$. Future Alone participants also had higher pain thresholds than No feedback control participants, $F(1,30)=17.91, p<.001, d=1.03$. Future Belonging participants showed a trend toward having lower pain threshold compared to No feedback control participants, $F(1$, $30)=3.43, p=.07$. The means and standard deviations are presented in Table 1 .

Future Alone participants also showed a substantial increase in their pain threshold from their baseline measurement. Results from ANOVA indicated that there was significant variation among the three social feedback groups in terms of changes in pain threshold from baseline to post-feedback measurement, $F(2,30)=21.96, p<.001$. A $2-1-1$ linear contrast revealed that Future Alone participants increased their pain threshold from baseline measurement significantly more than both Future Belongingness and No feedback control participants, $F(1,30)=38.07, p<$ .001 . A one-cell $t$-test confirmed that the difference between baseline and post-feedback pain 
threshold measurement among Future Alone participants was greater than zero, $t(10)=-4.83, p=$ .001 . These findings suggest that the increase in pain sensitivity was not just relative to participants in the other two conditions but was an absolute change from baseline measurements. Pain Tolerance

Socially excluded participants showed significantly higher levels of pain tolerance than all other participants. Results from ANCOVA on the pain tolerance scores indicated that there was significant variation between the three experimental groups, $F(2,30)=20.36, p<.001$. A 2 1 -1 linear contrast confirmed that Future Alone participants had higher overall pain tolerance than both Future Belongingness and No feedback control participants, $F(1,30)=40.60, p<.001$. Pairwise comparisons using the ANCOVA mean square error revealed that Future Alone participants had significantly higher pain thresholds than Future Belongingness participants, $F(1$, $30)=32.65, p<.001, d=1.41$. Future Alone participants also showed significantly higher pain tolerance than No feedback control participants, $F(1,30)=28.87, p<.001, d=1.33$. Future Belongingness and No feedback control participants did not differ in terms of their pain tolerance, $F<1$, ns.

Socially excluded participants substantially increased their pain tolerance from their baseline measurement. An ANOVA on the difference scores for pain tolerance revealed significant variation between the three experimental groups, $F(2,30)=22.28, p<.001$. A $2-1-1$ linear contrast showed that Future Alone participants increased their pain tolerance from baseline measurement significantly more than both Future Belongingness and No feedback control participants, $F(1,30)=44.49, p<.001$. A one-cell $t$-test confirmed that the difference between baseline and post-feedback pain tolerance measurement among Future Alone participants was greater than zero, $t(10)=-4.94, p=.001$, indicating that their tolerance was significantly higher after receiving the feedback than it had been beforehand.

\section{Mood and Emotion.}

To investigate the possible role of mood and emotion in shaping the observed effects, we tested for fluctuations in mood valence and arousal as a result of personality feedback. Two oneway ANOVAs were carried out using the valence and arousal subscales of the BMIS (Mayer \& Gaschke, 1988) as dependent measures. There was no significant variation between the three social feedback groups in terms of their reported mood valence, $F(2,30)=2.21, p=.13$. There was also no significant variation between the three social feedback groups in terms of their 
reported mood arousal, $F<1, n s$. Thus, the observed increases in pain tolerance and threshold among socially excluded participants were not due to differences in mood valence and arousal.

\section{Self-esteem and Rejection Sensitivity.}

To examine whether individual differences in global self-esteem or rejection sensitivity moderated the observed effects, we conducted a series of moderated multiple regressions that predicted participants' pain threshold and pain tolerance from their social feedback condition, their global self-esteem and rejection sensitivity score, and the centered interaction between social feedback condition and self-esteem or rejection sensitivity score. Baseline measurements of pain tolerance and threshold were entered as covariates in the first step of each regression equation. Results indicated that the social feedback condition to which participants had been assigned significantly predicted their post-feedback pain tolerance score, $\beta=.42, p<.001$, and post-feedback pain threshold score, $\beta=.46, p<.001$. Neither self-esteem nor rejection sensitivity significantly predicted post-feedback pain threshold or pain tolerance scores. Moreover, both interactions measuring post-feedback pain tolerance and threshold as a function of social feedback condition and self-esteem and rejection sensitivity were not statistically significant, both $p s>.20$. Thus, the observed increase in pain tolerance and threshold following rejection was independent of individual differences in global self-esteem and rejection sensitivity.

\section{Discussion}

Social exclusion produced increases in both pain threshold and pain tolerance, consistent with the hypothesis that people become less sensitive to physical pain as a result of having their need to belong thwarted. Participants who anticipated a lonely future showed greater tolerance and less sensitivity to physical pain than participants who experienced social acceptance or participants who received no personality feedback. They also showed significantly less sensitivity to physical pain than they themselves had shown on the baseline measures. The estimated effect sizes for the increases in pain threshold and pain tolerance among socially excluded participants were quite large (Cohen, 1977), both exceeding a standard deviation.

The results of Experiment 1 were not due to any differences in reported mood valence or mood arousal between participants in the three experimental groups. Future Alone participants did not report moods that differed significantly from those reported by Future Belonging or No feedback control participants. In addition, neither rejection sensitivity nor trait self-esteem 
played a moderating role in predicting the relationship between social exclusion on physical pain threshold and pain tolerance.

One possible limitation to Experiment 1 was that the social exclusion manipulation (i.e., telling participants they would have a lonely future) may have merely constituted a form of bad news to participants. From this perspective, the negative nature of the social exclusion feedback may have driven been the driving force behind the increases in pain threshold and pain tolerance instead of indicating anything specific about social exclusion. If this view is correct, participants should show increases in pain threshold and pain tolerance if they receive a negatively valenced future diagnostic forecast, regardless of whether it involves exclusion from others. We conducted Experiment 2 with an additional control group (Misfortune Control) that would enable us to test this alternative explanation.

\section{Experiment 2: Exclusion versus other Calamities}

Experiment 2 was conducted to replicate the findings of Experiment 1 and to test the alternative hypothesis that only a negatively valenced future diagnostic forecast was sufficient to produce increases in pain threshold and pain tolerance. In Experiment 1, participants who anticipated a lonely future showed increases in pain threshold and pain tolerance compared to participants who anticipated a future of social acceptance or who received no personality feedback. Thus, the only group of participants who showed increases in pain threshold and pain tolerance were those who received a negative future diagnostic forecast (e.g., Future Alone), whereas other participants received a relatively pleasant (e.g., Future Belonging) or neutral (e.g., No feedback control) diagnostic forecast showed relatively little change in their pain threshold and pain tolerance.

The major refinement of Experiment 2 was that some participants received feedback that they had a personality type that was likely associated with a future marred by negative events, but these events bore no relationship to participants' belongingness status. These participants were told that their personality profile indicated that they would have frequent accidents in the future, such as car accidents or other injurious mishaps. Participants assigned to this condition will be referred to Misfortune Control participants. The main prediction was that increased pain threshold and pain tolerance would be unique to social exclusion and not due to the negative valence of the future diagnostic forecast.

Method 
Participants. 30 right-handed undergraduates (24 women) participated in this study in exchange for partial course credit. Participants met the same requirements for participation as participants in Experiment 1. Participants were 83\% White and 17\% racial minority. The average age was 18.3 years.

Materials and procedure. Upon arrival to the laboratory, participants were told that the purpose of the experiment was to understand different aspects of personality, their relationship to verbal and non-verbal performance, and physical sensitivity. After giving informed consent, gave baseline measurements of pain threshold and pain tolerance ( 2 trials each) using a pressure algometer (Type II, Somedic, Inc., Solletuna, Sweden). The experimenter followed the same procedure for pain threshold and tolerance measurement used in Experiment 1. After completing the baseline measurements, participants completed a brief demographic questionnaire and the Eysenck Personality Questionnaire (EPQ; Eysenck \& Eysenck, 1975).

When participants had completed the EPQ, they were exposed to the same social exclusion manipulation used in Experiment 1 . To bolster the credibility of the personality measure, all participants received accurate feedback regarding their extraversion score. Based on random assignment, participants were then told they would either end up alone later in life (Future Alone), that they would have many lasting and meaningful relationships later in life (Future Belonging), or that they would become accident prone later in life (Misfortune Control) (see Twenge et al., 2001). Specifically, participants assigned to the Misfortune control condition were told:

You're likely to be accident prone later in life - you might break an arm or a leg a few times, or maybe be injured in car accidents. Even if you haven't been accident prone before, these things will show up later in life, and the odds are you will have a lot of accidents.

Participants then completed the Brief Mood Introspection Measure (BMIS; Mayer \& Gaschke, 1988) and a series of unrelated measures. After completing these materials, postfeedback measures of pain threshold and tolerance ( 5 trials each) were taken. Once participants had completed the pain threshold and tolerance measures, they were debriefed, given partial course credit, thanked, and dismissed.

Results

We again computed the omnibus $F$ statistic and performed a linear contrast comparing 
the pain threshold and tolerance of socially excluded participants (Future Alone) to non-socially excluded participants (Future Belonging, Misfortune Control). Post-feedback threshold and tolerance scores were compared using baseline threshold and tolerance scores as a covariate. In addition, a difference score was computed by subtracting baseline threshold and tolerance scores from post-feedback scores.

\section{Pain Threshold}

A future diagnostic forecast of social exclusion produced significant increases in pain threshold compared to participants who received a forecast of future belongingness or becoming accident prone. Results from ANCOVA on the pain threshold scores revealed significant variation between the three experimental groups, $F(2,27)=10.84, p<.001$. A $2-1-1$ linear contrast showed that Future Alone participants had substantially higher pain threshold scores compared to Future Belonging and Misfortune Control participants, $F(1,27)=21.35, p<.001$. Pairwise comparisons using the ANCOVA mean square error showed that Future Alone participants had significantly higher pain threshold scores than Future Belonging participants, $F(1,27)=18.46, p<.001, d=1.11$. In addition, Future Alone participants had higher pain threshold scores compared to Misfortune Control participants, $F(1,27)=14.13, p=.001, d=.99$. Future Belonging and Misfortune Control participants did not differ in their pain threshold scores, $F<1$, ns. The means and standard deviations are presented in Table 1.

Future Alone participants showed considerable increases in their pain threshold from their baseline measures compared to Future Belonging and Misfortune Control participants. An ANOVA on the difference in pain threshold scores revealed significant variation between the three experimental groups, $\mathrm{F}(2,27)=11.35, \mathrm{p}<.001$. A $2-1-1$ linear contrast demonstrated that Future Alone participants increased their pain threshold from baseline measurement significantly

more than both Future Belonging and Misfortune Control participants, $F(1,27)=22.44, p<.001$. A one-cell $t$-test confirmed that the difference between baseline and post-feedback pain threshold measurement among Future Alone participants was greater than zero, $t(9)=-3.14, p=.01$. Thus, feedback indicating social exclusion produced absolute increases in pain threshold from baseline.

\section{Pain Tolerance}

Social exclusion produced substantial increases in pain tolerance compared to participants who believed they would likely have many relationships or become accident prone later in life. ANCOVA on the pain tolerance scores revealed significant variation between the 
three experimental groups, $F(2,27)=9.66, p=.001$. A $2-1-1$ linear contrast showed that Future Alone participants had a significantly higher pain tolerance compared to Future Belonging and Misfortune Control participants, $F(1,26)=19.21, p<.001$. Pairwise comparisons using the ANCOVA mean square error demonstrated that Future Alone participants had significantly higher pain tolerance scores than Future Belonging participants, $F(1,27)=15.50, p=.001, d=$ 1.01. Future Alone participants also had significantly higher pain tolerance scores than Misfortune Control participants, $F(1,27)=13.98, p=.001, d=1.02$. Future Belonging and Misfortune Control participants did not differ in their pain tolerance scores, $F<1$, ns.

Socially excluded participants significantly increased their pain tolerance from baseline measurements compared to Future Belonging and Misfortune Control participants. ANOVA on the difference scores in pain tolerance revealed significant variation between the three experimental groups, $F(2,27)=10.39, p<.001$. A one-cell $t$-test confirmed that the difference between baseline and post-feedback pain tolerance measurement among Future Alone participants was greater than zero, $t(10)=-2.91, p<.02$. Thus, a future diagnostic forecast of social exclusion produced absolute increases in pain tolerance from baseline measurement, whereas a forecast of future social acceptance or of becoming accident prone did not increase pain tolerance.

\section{Discussion}

Experiment 2 replicated the results of Experiment 1 and ruled out the alternative explanation that increases in pain threshold and pain tolerance were simply due to the negative nature of the social exclusion feedback. Future Alone participants increased their pain threshold and pain tolerance from baseline significantly more than participants who experienced social acceptance. Socially excluded participants also had substantially higher pain threshold and pain tolerance scores compared to participants who received a negatively valenced future diagnostic forecast that did not affect their future belongingness status. The finding that socially accepted participants decreased their pain thresholds from baseline (Experiment 1) did not replicate in Experiment 2. These results suggest that observed increases in both pain threshold and pain tolerance were unique to social exclusion.

\section{Experiment 3: Not Feeling Future Pain}

Experiment 3 had two main purposes. First, we tested whether social exclusion would have implications for affective forecasting. Affective forecasting involves simulating emotional 
reactions to possible future events. Exclusion causes the emotion system to cease functioning properly, indeed muting and numbing emotional reactions. It is therefore possible that hypothetical emotional reactions to future (i.e., imagining how you would feel) also will be numbed. Accordingly, rejected participants (who reported relative emotional numbness in Experiments 1 and 2) should make affective forecasts of relative emotional numbness compared to accepted and control participants. That is, rejected participants should report less happiness when forecasting their emotional reaction to a positive event, and less sadness and distress when forecasting their emotional reaction to a negative event. Socially accepted and control participants, in contrast, should exhibit the previously documented overestimation of their happiness or sadness to future events (e.g., Wilson et al., 2004). Next, we tested whether altered increases in pain threshold and pain tolerance played a mediating role in the predicted unemotional affective forecasts among socially excluded participants.

Method

Participants. Thirty right-handed undergraduates (19 women) participated in this experiment in exchange for partial course credit. Participants met the same requirements for participation as participants in Experiments 1 and 2. Participants were 77\% White and 23\% racial minority. The average age was 18.6 years.

Materials and procedure. Participants arrived at the laboratory individually for an experiment ostensibly concerned with the relationship between personality, verbal and nonverbal behaviors, and physical sensitivity. After giving informed consent, participants completed baseline measurements of pain threshold and pain tolerance ( 2 trials each). Participants then completed a personality test and were exposed to the same social exclusion manipulation used in Experiment 1. By random assignment, participants were told that they had a personality type in which they would likely end up alone (Future Alone) or that their personality type was diagnostic of a future filled with many rewarding and lasting relationships (Future Belonging). Another group was not given any feedback on their personality test (No feedback-control).

After receiving their personality feedback, participants completed the Brief Mood Introspection Scale (BMIS; Mayer \& Gaschke, 1988) and affective forecasting measures. The affective forecasting measures were modeled after previous research by Wilson and colleagues (Wilson, Wheatley, Meyers, Gilbert, \& Axsom, 2000). Participants were reminded that the Florida State football team was scheduled to play the University of Florida on November 20, 
2004 (approximately 2 months into the future), and were asked to predict what their level of overall happiness would be directly after the game if Florida State beat the University of Florida and what it would be if Florida State lost the game. All responses were made on 7-point scales that ranged from 1 (extremely unhappy) to 7 (extremely happy). To ensure that differences in affective forecasting were not due to differences in concern for the outcome of the game, participants also reported to what degree they considered themselves a Florida State University football fan and to what extent they cared whether Florida State won their game against the University of Florida. These two measures were highly correlated $(r=.50, p=.005)$ and were combined to create a Florida State football "fan" index.

When participants had completed the BMIS and affective forecasting measures, participants completed additional measurements of pain threshold and pain tolerance ( 5 trials each). Participants were then debriefed, thanked for their time, given partial course credit, and dismissed.

\section{Results}

\section{Pain threshold and Pain tolerance: Replication}

As in Experiments 1 and 2, a future diagnostic forecast of social exclusion produced significant increases in pain threshold compared to participants who anticipated a future filled with meaningful relationships or who received no feedback on their personality test. ANCOVA on the pain threshold scores using baseline pain threshold scores as a covariate revealed significant variation between the three experimental groups, $F(2,27)=9.07, p=.001$. A $2-1-1$ linear contrast also showed that Future Alone participants had significantly higher pain threshold scores than Future Belonging and No feedback control participants, $F(2,27)=17.96, p<.001$. A one-cell $t$-test confirmed that the difference between baseline and post-feedback pain threshold measurement among Future Alone participants was greater than zero, $t(9)=-2.50, p=.03$.

Socially excluded participants also showed increased pain tolerance compared to participants who experienced social acceptance and participants who received no feedback on a personality test. An ANCOVA on the pain tolerance scores revealed significant variation between the three experimental groups, $F(2,27)=18.91, p<.001$. A $2-1-1$ linear contrast confirmed that Future Alone participants had significantly higher pain tolerance scores than both Future Belonging and No feedback control participants, $F(2,27)=37.69, p<.001$. A one-cell $t$ test confirmed that the difference between baseline and post-feedback pain threshold 
measurement among Future Alone participants was greater than zero, $t(9)=-2.93, p=.02$. Thus, Future Alone participants showed substantial and absolute increases in both pain threshold and pain tolerance. The means and standard deviations are presented in Table 1.

\section{Affective Forecasting}

Replicating previous affective forecasting research, Future Belonging and No feedback control participants predicted strong emotional responses to a Florida State victory and defeat. Most relevant to the current investigation, however, was the finding that participants in the Future Alone condition reported relatively neutral emotional reactions to both a Florida State victory and defeat. An ANOVA on the question "Please predict what your overall happiness would be right after the game if Florida State beats Florida" revealed significant variation between the three experimental groups, $F(2,27)=20.66, p<.001$. A $2-1-1$ linear contrast confirmed that Future Alone participants predicted a significantly lower degree of happiness in response to Florida State defeating the University of Florida compared to both Future Belonging and No feedback control participants, $F(2,27)=41.42, p<.001$. Pairwise comparisons using the ANOVA mean square error indicated the Future Alone participants $(M=4.70, S D=.99)$ predicted less happiness over Florida State defeating the University of Florida compared to Future Belonging participants $(M=6.60, S D=.69), F(1,27)=25.99, p<.001$. Future Alone participants $(M=4.70, S D=.99)$ also predicted a less happy response to a Florida State victory compared to No feedback control participants $(M=6.70, S D=.67), F(1,27)=29.51, p<.001$. Future Belonging and No feedback control participants did not differ significantly in terms of how happy they would be if Florida State beat the University of Florida, $F<1$, ns.

Similar analyses were conducted on responses to the question, "Please predict what your overall happiness would be right after the game if Florida State loses to Florida." ANOVA revealed significant variation between the three experimental groups, $F(2,27)=5.94, p=.007$. A 2 -1 -1 linear contrast confirmed that Future Alone participants predicted greater happiness in response to Florida State being beaten by the University of Florida than both Future Belonging and No feedback control participants, $F(2,27)=11.20, p=.002$. Pairwise comparisons using the ANOVA mean square error indicated that Future Alone participants $(M=3.50, S D=.71)$ predicted significantly greater happiness to a Florida State loss than Future Belonging participants $(M=2.30, S D=1.34), F(1,27)=6.29, p=.02$. Future Alone participants $(M=3.50$, $S D=.71)$ also predicted a significantly happier emotional response to a Florida State loss than No 
feedback control participants $(M=1.90, S D=1.10), F(1,27)=14.96, p=.001$. Future Belonging and No feedback control participants did not predict significantly different emotional responses to a Florida State loss, $F<1, n s$.

To examine possible discrepancies in predicted happiness between winning and losing, an index of differential predicted happiness was created. To create the index, scores to the question "Please predict what your overall happiness would be right after the game if Florida State beats Florida" were subtracted from scores to the question "Please predict what your overall happiness would be right after the game if Florida State loses to Florida." Thus, possible scores ranged from 6 (for participants who expressed that they would be maximally happy if Florida State won and maximally unhappy if Florida State lost) to -6 (for participants who expressed that they would be maximally happy if Florida State lost and maximally unhappy if Florida State won). Participants who did not differ in their affective forecasts would therefore have differential predicted happiness index scores close to 0 .

Results indicated that there was significant variation between the three experimental groups, $F(2,27)=16.22, p<.001$. A $2-1-1$ linear contrast confirmed that Future Alone participants had significantly lower differential predicted happiness scores (indicating greater predictions of emotional numbness) compared to both Future Belonging and No feedback control participants, $F(1,27)=31.91, p<.001$. Pairwise comparisons revealed that Future Alone participants $(M=1.20, S D=1.23)$ had significantly lower differential predicted happiness scores compared to Future Belonging participants $(\mathrm{M}=4.30, \mathrm{SD}=1.77), F(1,27)=20.49, p<.001$. Future Alone participants $(M=1.20, S D=1.23)$ also had significantly lower differential predicted happiness scores compared to No feedback control participants $(M=4.80, S D=1.55), F(1,27)=$ $27.64, p<.001$. Future Belonging participants did not differ from No feedback control participants in terms of their differential predicted happiness scores, $F<1, n s$.

Supplementary analyses were conducted to test whether the exclusion, acceptance, and control groups differed in the degree to which they perceived themselves as Florida State football fans and the degree to which they cared about the outcome of the upcoming Florida State versus University of Florida football game. Results from ANOVA revealed no significant variation between the three groups on the "fan" index, $F(2,27)=2.29, p=.12$. Pairwise comparisons revealed that Future Alone participants $(M=10.30, S D=2.63)$ had scores on the fan index that were not significantly different from Future Belonging participants $(M=8.90, S D=3.45), F(1$, 
$27)=1.04, p=.32$. Future Alone participants also had scores on the fan index that were not different from No feedback control participants $(M=11.60, S D=2.27), F(1,27)=1.40, p=.25$. Future Belonging participants $(M=8.90, S D=3.45)$ had scores on the fan index that were marginally lower than No feedback participants $(M=11.60, S D=2.27), F(1,27)=4.28, p<.06$. Thus, the attenuated forecasts (in the Future Alone condition) of affective reactions to the future game outcome were not due to feeling oneself as less a fan or feeling less interested in the football game.

\section{Mood and Emotion}

To assess the possibility that the observed effects were due to difference in mood, two one-way ANOVAs were conducting using the mood valence and mood arousal subscales of the BMIS (Mayer \& Gaschke, 1988) as dependent measures. Both ANOVAs revealed no significant variation between the three experimental groups, both $F_{\mathrm{S}}<1.28, p \mathrm{~s}>.30$. These results suggest that increases pain threshold and pain tolerance following social exclusion were not the result of differences in mood.

\section{Mediational Analyses}

To test the hypothesis that affective forecasts of low differential happiness were mediated by increases in pain tolerance and threshold, we conducted separate mediational analyses for pain threshold and tolerance scores using multiple regression (as described in Kenny, Kashy, \& Bolger, 1998). To increase statistical power, scores on the differential happiness index were used as the dependent variable in both mediational analyses. Results from a Sobel test (Sobel, 1982) revealed that affective forecasts of low differential happiness among socially excluded participants were mediated by their increased pain threshold, $z=2.21, p<.03$. An additional Sobel test showed that affective forecasts of low differential happiness exhibited by socially excluded participants was mediated by their increased pain tolerance, $z=2.46, p=.01$. Thus, social exclusion led to relatively unemotional affective forecasts to future football outcomes, and this relationship was accounted for by decreased sensitivity and increased tolerance to physical pain.

\section{Discussion}

Experiment 3 provided support for the hypothesis that increased pain threshold and pain tolerance among socially excluded participants led to emotional insensitivity. As in Experiments 1 and 2, socially excluded participants exhibited increases in both pain threshold and pain 
tolerance compared to accepted and control participants. Excluded participants also reported emotional states that did not differ from accepted and control participants. It is difficult to grasp whether excluded participants experienced no emotion or whether they were simply refusing to admit that they are upset. If the latter is true, however, excluded participants should be willing to talk about future emotional reactions, such as being happy in their University were to win an important football game two months in the future. The findings of Experiment 3 provide evidence that social exclusion causes the emotion system to shut down, possibly in connection with the observed numbness to pain, which left excluded participants temporarily unable to simulate future emotional reactions. Socially excluded participants not only failed to report much in the way of current emotion, they also predicted little in the way of a future emotional response to a major meaningful event. Excluded participants predicted report less happiness when forecasting their emotional reaction to a positive event and greater happiness when forecasting their emotional reaction to a negative event, compared to participants in the other conditions. It would have been plausible for exclusion to cause people to identify either more or less strongly with FSU and its football team, but they did not. In any case, the failure of rejected people to predict much in the way of an emotional reaction to future football outcomes was not mediated by changes in their identification with FSU or expressed concern with the outcome of the FSU versus University of Florida football game. After hearing that they were likely to be alone later in their lives, they retained their (relatively strong) identification with their university, but they did not think they would feel much emotion about the outcome of its football game against a major rival. This suggests that the rejection led the emotion system to become relatively unresponsive and insensitive to physically and emotionally distressing events.

Most important, however, was the finding that the relatively unemotional affective forecasting among socially excluded participants was mediated by increased physical pain threshold and pain tolerance. This extends the findings of Experiments 1 and 2 by showing that social exclusion leads people to respond unemotionally to current events and to predict unemotional reactions to possible future events. Rejected participants predicted less happiness to a future positive event and greater happiness to a future negative event, and this relationship was explained by their increased pain threshold and pain tolerance. Thus, the results of Experiment 3 demonstrated that the body responds to social exclusion feedback with a kind of physical shock reaction that includes numbness and insensitivity to physical pain, and this dampens emotional 
reactions as well.

\section{Experiment 4: Not Feeling Someone Else's Pain}

Experiments 1-3 found that social exclusion seems to make people relatively numb to physical pain, and Experiment 3 further suggested that the insensitivity to physical pain is linked to emotional insensitivity. Experiment 4 provided a further test of this link. If one's emotional system temporarily shuts down, one should be less capable of empathy and sympathy, and so one's reaction to another person's suffering should be muted. Indeed, participants in Experiment 4 were asked to empathize with someone who were suffering about something to which the participants ought seemingly to be extra sensitive, namely social rejection. Would social exclusion render people emotionally insensitive to another person's romantic rejection? Again, if people experienced negative affect in response to social exclusion but were merely reluctant to admit it, then they might still be willing to show feeling for someone else's suffering. But if rejection causes people's emotion system to shut down, then they might be unable to achieve an emotional, empathic identification with someone else.

Participants were given an opportunity to empathize with a same-sex participant regarding the recent dissolution of his or her romantic relationship. For this, we adapted a procedure used in previous studies of empathy and altruism (Batson, Klein, Highberger, \& Shaw, 1995). After receiving their bogus personality feedback and reporting their mood, participants were informed that another experiment conducted in the same laboratory needed a participant to read an essay ostensibly written by another participant about something that recently happened to him or her. Participants then read a short essay in male or female handwriting that described the recent dissolution of his or her romantic relationship. (The other person's ostensible gender was matched to the participant's, in order to facilitate sympathy and identification.) Participants were then asked a series of questions aimed at measured the degree to which they felt empathy-related emotions (e.g., sympathetic, warm, compassionate) toward the other participant.

The social exclusion manipulation was the same bogus personality feedback manipulation used in Experiments 1-3. Participants received feedback that they would end up alone (Future Alone) or that they would have great relationships later in life (Future Belonging). An additional group of participants received no feedback on their personality test (No feedback control). The main predictions were that social exclusion would lead to less empathy toward the participant who wrote the essay, and that increases in pain threshold and pain tolerance would 
mediate the relationship between social exclusion and emotional insensitivity to another person's suffering.

\section{Method}

Participants. Thirty-one undergraduates (21 women) participated in this experiment in exchange for partial course credit. All but one of the participants met the same requirements for participation as participants in Experiments 1-3. The participant who did meet the requirements for participation was left-handed and all pain threshold and pain tolerance measurements were taken from this participant's non-dominant hand. Inclusion of the left-handed participant in the final data set did not change the results of the experiment significantly and therefore this participant was included in all analyses. Participants were $71 \%$ White and $29 \%$ racial minority. The average age was 18.5 years.

Materials and procedure. The materials and procedure for Experiment 4 were similar to Experiments 1-3. Participants arrived to the laboratory individually for an experiment ostensibly concerned with the relationship between different aspects of personality, verbal and non-verbal performance, and physical sensitivity. After giving informed consent, participants completed the EPQ (Eysenck \& Eysenck, 1975). To enhance the perceived credibility of the test, participants then received accurate feedback regarding their extraversion. By random assignment, participants were told that they had a personality type where they would likely end up alone (Future Alone) or a personality type where they would have many meaningful and lasting relationships later in life (Future Belonging). An additional group of participants were assigned to receive no information regarding their personality (No feedback control).

After receiving their personality feedback, participants completed the BMIS (Mayer \& Gaschke, 1988). Participants then completed a measure of empathy. The experimenter explained to the participant that there was another experiment going on in the laboratory in which one participant writes an essay about something going in his or her life and another participant reads the essay and answers some questions about it. Participants were told that the participant who was supposed to read and respond to the essay did not show up for the experiment. The experimenter explained to participants that they would be reading and responding to the essay because it would not take a large amount of time and would help the other experimenter tremendously. Participants were then handed a manila folder that contained a handwritten essay 
(in male or female handwriting ${ }^{1}$ ) and short questionnaire. The content of the essay was adapted from Batson et al. (1995). The essay read (in part):

Two days ago I broke up with my (girlfriend) boyfriend. We've been going together since our junior year in high school and have been really close, and it's been great being at FSU together. I thought (s)he felt the same, but things have changed. Now, (s)he wants to date other people. (S)He says (s)he still cares a lot about me, but (s)he doesn't want to be tied down to just one person. I've been real down. It's all I think about. My friends all tell me that I'll meet other (girls)guys and they say that all I need is for something good to happen to cheer me up. I guess they're right, but so far that hasn't happened.

After reading the essay, participants answered several questions about how they felt toward the author of the essay. Using a 12-point scale $(0=$ not at all, $11=$ extremely), participants reported how sympathetic, warm, compassionate, softhearted, and tender they felt toward the author of the essay. These adjectives have been used in previous research to measure empathy (Batson, 1987, 1991; Batson et al., 1995). The internal reliability for the empathy-related adjectives was good (Cronbach's $\alpha=.92)$ and therefore an empathy index was created by summing responses to the five empathy adjectives (sympathetic, warm, compassionate, softhearted, and tender). Thus, possible scores on the empathy index ranged from 0 to 55 with higher scores indicating greater emotional responsiveness toward the essay's author.

When participants had read and responded to the essay, participants placed the essay and the questionnaire in an envelope, sealed it, and handed it back to the experimenter. The experimenter then left the laboratory ostensibly to return the envelope to the experimenter for the other study. When the experimenter returned, the participant completed additional measurements of pain threshold and pain tolerance ( 5 trials each). Participants were then debriefed, thanked for their time, given partial course credit, and dismissed.

\section{Results}

\section{Pain threshold and Pain Tolerance: Replication}

As in the previous three experiments, a future diagnostic forecast of social exclusion produced increases in pain threshold compared to participants who anticipated a future filled with social acceptance or who received no feedback on a personality test. ANCOVA on the pain

\footnotetext{
${ }^{1}$ The essay was handwritten by either a male or a female research assistant. No participants expressed suspicion about the gender of the author of the essay. In fact, many participants commented during the debriefing that the handwriting was indicative of either a male or female author.
} 
threshold scores revealed significant variation between the three experimental groups, $F(2,28)=$ 54.12, $p<.001$. A $2-1-1$ linear contrast confirmed that Future Alone participants had significantly higher pain threshold scores compared to Future Belonging and No feedback control participants, $F(2,28)=108.15, p<.001$. A one-cell $t$-test confirmed that the difference between baseline and post-feedback pain threshold measurement among Future Alone participants was significant, $t(9)=-5.99, p<.001$.

Socially excluded participants also demonstrated a significantly higher tolerance for pain than participants assigned to the other experimental groups. ANCOVA on the pain tolerance scores showed significant variation between the three experimental groups, $F(2,28)=45.25, p<$ .001. A 2 -1 -1 linear contrast confirmed that Future Alone participants had significantly higher pain tolerance scores than participants who did not experience social exclusion (i.e., Future Belonging and No feedback control), $F(2,28)=89.99, p<.001$. A one-cell $t$-test confirmed that the difference between baseline and post-feedback pain threshold measurement among Future Alone participants was significantly greater than zero, $t(10)=-6.69, p<.001$. The means and standard deviations are presented in Table 1.

\section{Empathy}

Socially excluded participants showed less empathic concern for another participant who had recently experienced romantic rejection than participants who experienced social acceptance or participants assigned to the control group. ANOVA on the 5-item empathic emotion index revealed significant variation between the three experimental groups, $F(2,28)=10.10, p<.001$. A 2 -1 -1 linear contrast demonstrated that Future Alone participants reported feeling less sympathy, compassion, warmth, tenderness, and softheartedness toward the participant who had recently experienced relationship loss, as compared to Future Belonging and No feedback control participants, $F(2,28)=19.67, p<.001$. Pairwise comparisons using the ANOVA mean square error showed that Future Alone participants $(M=32.80, S D=7.66)$ had significantly lower scores on the empathy index compared to Future Belonging participants $(M=42.00, S D=5.79)$, $F(1,28)=12.37, p=.002, d=1.35$. Future Alone participants $(M=32.80, S D=7.66)$ also had lower scores on the empathy index compared to No feedback control participants $(M=43.55$, $S D=3.59), F(1,28)=17.67, p<.001, d=1.79$. Future Belonging participants did not differ in their empathy scores compared to No feedback control participants, $F<1, n s$. Thus, Future Alone participants expressed less emotional responsiveness to another person who had 
experienced exclusion compared to Future Belonging and No feedback control participants. Mood and Emotion

To determine whether the observed effects were due to difference in mood, two one-way ANOVAs were conducting using the mood valence and mood arousal subscales of the BMIS (Mayer \& Gaschke, 1988) as dependent measures. Both ANOVAs revealed no significant variation between the three experimental groups, both $F_{\mathrm{s}}<1.79, p \mathrm{~s}>.20$. Thus, increases pain threshold and pain tolerance following social exclusion were not caused by differences in mood. Mediational Analyses

To examine whether the lack of empathic responding among socially excluded participants was mediated by increased pain tolerance and pain threshold, mediational analyses were conducted using regression (Kenny et al., 1998). Results from a Sobel test indicated that the lack of empathic responding exhibited by socially excluded participants was mediated by their increased pain threshold, $z=3.65, p<.001$ (see Figure 2). In addition, the relationship between exclusion condition and empathic responding was mediated by increased pain tolerance, $z=4.61$, $p<.001$ (see Figure 3). Thus, the increase in tolerance and threshold for physical pain following social exclusion accounted for the relationship between social exclusion and lack of empathic concern to others who had also experienced social exclusion.

\section{Discussion}

Experiment 4 provided additional evidence that the emotion system temporarily ceases to function normally following social exclusion. This led socially excluded participants to show less emotional responsiveness toward another participant who demonstrated distress at the recent dissolution of his or her romantic relationship, compared to socially accepted and control participants. To be sure, the opposite finding would not have been completely surprising and would not have been a major problem for our theory. On an a priori basis, it would have been plausible that empathy toward another person who has recently experienced social exclusion would have been an exception to the general numbness theory proposed in the current paper. Socially excluded people experience a temporary shutdown in the emotion system that buffers them from feeling the negative effects of their own exclusion, but they might plausibly have been able to sympathize with someone else who has also experienced exclusion. Socially excluded people might at least have felt sorry for the person who had experienced exclusion, or they might have said that they understood how sad the situation might have been. Instead, their ratings 
expressed little or no empathy toward a person who had experienced exclusion. In fact, one participant in the Future Alone condition commented "tough shit" upon reading about the other participant's romantic woes-a comment that clearly indicates an uncharitable and unsympathetic attitude toward another person's pain.

Furthermore, the increases in pain threshold and pain tolerance among socially excluded participants mediated the relationship between social exclusion and lack of empathy toward the other participant. This supports the general theory that the emotion system temporarily ceases to function properly following exclusion, which leads to physical numbness and emotional insensitivity to others. As in Experiments 1-3, excluded participants became more numb to physical pain compared to participants who did not experience exclusion. The findings of Experiment 4 also showed that excluded participants suffered deficits in their ability to empathize with another person who had recently experienced social exclusion. Responding to physically painful stimuli and responding with empathy toward people in distress are both behaviors that require little in the way of practice or learning. People who experience social exclusion, however, apparently become deficient in their ability to detect physical pain and express empathy toward another person who is in distress.

One possible limitation of Experiment 4 was that the message used in inducing empathy in participants was closely related to social exclusion. Although the essay used in Experiment 4 has been used in previous research to evoke general empathy (Batson et al., 1995), the lack of empathic responding among socially excluded participants may have been due to the author of the essay having also experienced a form of social exclusion. The idea of rejection may have been too close for comfort for excluded participants, an issue that was particularly sensitive. That is, excluded participants may have exhibited reduced empathy with another rejected person because the other person's rejection may have reminded them of their own recent social exclusion.

This raises the theoretical issue of whether emotional numbness following social exclusion is merely a psychological stratagem that rejected people use to ward off the threatening aspects of their exclusion - or is the emotional numbness a physiologically-based defense mechanism that creates numbness in general? If emotional numbness is merely a psychological stratagem, excluded people should be able respond emotionally toward another person unless doing so will increase any negative consequences of their recent exclusion experience. If, 
however, emotional numbness is part of a more general, physiologically-based defense mechanism that creates widespread numbness, socially excluded people should respond with less empathy toward another person people regardless of whether the person experienced social exclusion or not. In Experiment 5, participants were presented with an opportunity to empathize with another person who was experiencing physical pain and discomfort.

\section{Experiment 5: I can't feel another person's physical pain}

The main purpose of Experiment 5 was to replicate the findings of Experiment 4 and to test the alternative explanation that the results of Experiment 4 were due to the empathic message relating to social exclusion instead of a general personal distress. Experiment 4 showed that excluded participants did not feel empathy or sympathy toward another person who had been rejected. If, however, excluded participants reported less empathy out of a defensiveness to ward off the negative effects of their own exclusion experience, excluded participants should be willing and able to feel empathy toward someone suffering from physical pain. Experiment 5 provided participants with an opportunity to empathize another person who had recently sustained a physically painful injury. For this, participants read a brief message ostensibly written by another participant in a previous experiment. The message, which was designed for the current experiment, described an FSU student who broke his or her leg in intramural sports and was experiencing physical pain and difficulty getting around campus since his or her accident. This measure of empathy had the advantage of testing the alternative explanation that empathizing with another person's physical pain may be different from another person's social exclusion, particularly among participants who experienced social exclusion. If the effects of social exclusion are part of a physiologically-based defense mechanism that causes widespread physical and emotional numbness, excluded participants should become more numb to the of another person's pain compared to participants who do not experience social exclusion.

Exclusion was manipulated by having participants complete a vivid recall task in which they completed a brief autobiographical narrative recalling a time they experienced social rejection, social acceptance, or an unrelated event. This was meant to prime participants with thoughts of their relevant experience, which would in turn influence responding on a questionnaire designed to measure empathy. Previous research has shown that real and imagined events activate many of the same neural and psychological processes (Kosslyn et al., 1999; McGuire et al., 1993), and other research has shown the exclusion vivid recall task evokes 
responses similar to those found in manipulations of immediate rejection (Gardner, Pickett \& Brewer, 2000; Pickett, Gardner, \& Knowles, 2004). It was predicted that the current manipulation of rejection would produce the same emotional numbness as in excluded participants in Experiments 1-4. Since increases in pain threshold and pain tolerance in response to social exclusion were found consistently in Experiments 1-4, pain threshold and pain tolerance were not measured in the current experiment. The main prediction of Experiment 5 was that socially rejected participants would express less sympathy toward the author of the essay compared to accepted and control participants.

An additional refinement of Experiment 5 was an alternative measure of mood and emotion. Instead of the Brief Mayer Introspection Scale (BMIS), participants completed the Positive and Negative Affect Schedule (PANAS; Watson, Clark, \& Tellegan, 1988). Using an alternative measure of mood and emotion allowed us to rule out the possibility that the lack of mood effects in Experiments 1-4 were related to the instrument of measurement.

\section{Method}

Participants. One-hundred twenty-five participants (84 female) participated in this study in exchange for partial course credit. Nine participants were discarded from all analyses due to incomplete questionnaire packets (thus there were originally 134 participants). Participants were $74 \%$ White and $26 \%$ racial minority. The average age was 18.5 years.

Materials and procedure. Participants arrived at a large classroom in groups of 10-20 for a study ostensibly concerned with how people understand each other. After giving informed consent, participants completed a short questionnaire packet that contained instructions for an autobiographical narrative, a mood questionnaire, and additional materials aimed at measuring empathic responding. By random assignment, participants were assigned to one of three autobiographical narrative conditions: social rejection, social acceptance, and control.

The instructions for the social rejection narrative read: "On the next pages, you will write an essay about a time when you experienced rejection or exclusion by others. Think of a time when you felt that others did not want to be in your company and when you did not feel a strong sense of belongingness with another person or group. Nearly everyone has experienced such an experience more than once; please choose an especially important and memorable event." The instructions urged participants to describe the rejection experience in as thorough detail as possible and to provide the "full story." The other half of the participants wrote about a 
childhood experience of social acceptance. The instructions for the social acceptance narrative mirrored the social rejection instructions and only replaced words that dealt directly with the experience of rejection or acceptance. For example, "experienced rejection or exclusion by others" was replaced with "experienced social acceptance from others," and "did not want to be in your company and when you did not feel a strong sense of belongingness with another person or group" was replaced with "wanted to be in your company and when you felt a strong sense of belongingness with another person or group." The instructions for the social rejection and acceptance narrative were identical in all other respects. Participants assigned to the control condition were instructed to write a detailed essay about one of the things he or she did the previous day. These participants were instructed to be detailed enough in the essay so that someone reading you he or she wrote might "even picture themselves in that situation."

After participants completed writing their narrative, participants completed the Positive and Negative Affect Schedule (PANAS; Watson, Clark, \& Tellegan, 1988). Participants then read a short vignette that depicted a college student (of unknown gender) and was meant to evoke empathic responding from participants. The vignette read (in part):

Two days ago I broke my leg playing intramural sports. I've been playing on the same intramural team for the past three years and I'm upset that my season has been cut short. I'm experiencing pain because of my injury. I'm also having a tough time getting around campus, as there are lots of hills and stairs that make it hard to use my crutches on. The parking people won't let me get a handicapped permit because they said my injury was only temporary. I've been real down. It's all I think about.

Participants then answered a series of questions about how they felt toward the author of the essay. Using a 12-point scale $(0=$ not at all, $11=$ extremely), participants reported how sympathetic, warm, compassionate, softhearted, and tender they felt toward the author of the essay. The internal reliability of these five items was good (Cronbach's $\alpha=.86$ ) and therefore an empathy index was created by summing responses to these five items. When participants had finished the empathy rating task, they were debriefed, given partial course credit, thanked for their time, and dismissed.

Results 


\section{Empathy}

Participants who wrote about a time they experienced social rejection showed significantly less empathy toward the author compared to participants in the other two conditions. ANOVA on the 5-item empathic emotion index revealed significant variation between the three experimental groups, $F(2,122)=6.72, p=.002$. A $2-1-1$ linear contrast confirmed that socially rejected participants felt significantly less sympathy, warmth, compassion, tenderness, and softheartedness toward the author of the essay compared to both socially accepted and control participants, $F(1,122)=12.79, p=.001$. Pairwise comparisons using the ANOVA mean square error showed that rejected participants $(M=26.33, S D=9.42)$ empathized with the essay author significantly less than accepted participants $(M=31.82, S D=$ $8.65), F(1,122)=7.53, p=.007, d=61$. In addition, rejected participants $(M=26.33, S D=9.42)$ showed less empathic concern toward the essay author compared to control participants $(M=$ $32.96, S D=8.43), F(1,122)=12.21, p=.001, d=.74$. Socially accepted and control participants did not differ significantly in terms of how much they empathized with the essay author, $F<1$, $n s$. Thus, rejected participants were quite unsympathetic toward a member of their peer group who had suffered a physically painful injury and was having difficulty adjusting to the changes brought about by the injury. These results suggest that rejection brings about a lack of empathic responding toward others, regardless of whether the person has experienced rejection or another traumatic and physically painful event.

\section{Mood and emotion.}

To rule of the possibility that the effects were due to emotional distress, two one-way ANOVAs were conducting using the Positive Affect (PA) and Negative Affect (NA) subscales of the PANAS (Watson et al., 1988) as dependent measures. Results indicated that there was no significant variation between the three experimental groups in terms of reported PA, $F(2,122)=$ $1.31, p=.27$. The three groups also did not differ with respect to their reported NA, $F(2,122)=$ $1.89, p=.16$. Thus, decreased empathic responding among rejected participants was not due their having different moods than accepted and control participants.

\section{Discussion}

Experiment 5 provided evidence that rejected participants expressed less emotional responsiveness toward a person in physical pain compared to accepted and control participants. Socially rejected participants showed less empathy toward another person who was experiencing 
physical pain and discomfort due to a broken leg. Socially accepted and control participants, in contrast, showed significantly greater levels of empathic concern toward the author of the essay. These findings provide converging evidence that the emotion system temporarily ceases functioning properly following social exclusion, which leads to numbness to physical pain and emotional numbness toward another person in physical pain.

\section{General Discussion}

Social exclusion threatens a fundamental human motivation for strong and stable relationships. Such a threat strikes at the core of human psychological and physical well-being. Social exclusion has destructive effects on mental and physical well-being, but socially excluded people frequently report relatively numb emotional states. This paradox leaves open the mystery of why socially excluded people often respond to such a disturbing event as social exclusion in an emotionally numb manner. One possible explanation for this anomalous emotional responding following social exclusion is that the emotion system temporarily shuts down, leaving a person momentarily unable to respond to emotional events in a customary fashion. This should lead to numbness to physically painful stimuli, which should in turn lead to signs of emotional insensitivity.

The first goal of the current investigation was to investigate whether social exclusion causes people to lose sensitivity to physical pain. In a recent review, MacDonald and Leary (2005) argued persuasively that social exclusion is experienced as painful because reactions to rejection incorporate aspects of the physical pain system (see also Eisenberger et al., 2003; Eisenberger \& Lieberman, 2004). Citing research primarily with non-human animals, MacDonald and Leary (2005) provided compelling evidence in support of a link between social and physical pain. The results of the current investigation offered results that were in agreement with MacDonald and Leary (2005) and showed that the link between social and physical pain in non-human animals appears to be true for humans also. Across four experiments, socially excluded participants consistently showed both decreased sensitivity and increased tolerance to physical pain compared to socially accepted and control participants. The estimated effect size of the difference in pain threshold and pain tolerance between socially excluded participants and participants in the other conditions was consistently large, exceeding the criteria typically used to describe large effects (Cohen, 1977). Thus, participants responded to the social exclusion feedback by growing increasingly numb to physical pain stimuli, and these increases in pain 
threshold and pain tolerance were large in comparison to participants who experienced social acceptance, received a negatively valenced future diagnostic forecast, or who received no feedback on their personality test.

The second goal of the current investigation was to examine whether insensitivity to physical might explain the emotional numbness following social exclusion. In all five experiments, excluded participants reported emotional states that did not differ significantly from socially accepted and control participants. Admittedly, these results suffer from the uncertainties that accompany the use of self-reports of emotional responding, especially the idea that excluded participants might be reluctant to admit that they are upset over the experimental feedback. But excluded participants should be willing and able to predict future emotional reactions or empathize with others. The results of Experiments 3-5 showed that excluded participants were temporarily unable to predict emotional reactions to future events of empathize with others' suffering. Social exclusion feedback made people predict less happiness over a future football victory and less sadness over a possible defeat. Social exclusion also led participants to become less empathetic and sympathetic toward another person who had just suffered a relationship loss. And recalling a past experience of social exclusion made people less sympathetic toward a student who was suffering over a broken leg. These findings suggest that social exclusion produces a sweeping shutdown of the emotional system.

Thus, the findings from the current experiments indicate that the body responds to social exclusion in the same manner as it responds to physical injury. Exclusion produces a biochemical reaction that leads to temporary numbness to physical pain. This physical numbness, in turn, extends to emotional responding and results in emotional insensitivity. Mediational analyses in Experiments 3 and 4 confirmed that physical numbness to pain accounted for the relationship between social exclusion and emotional insensitivity.

The findings of Experiment 3 make a novel contribution to the affective forecasting literature by identifying a moderating variable to the previously documented pattern of people overestimating the impact of future emotional events on their lives (e.g., Wilson \& Gilbert, 2003). Exclusion temporarily disrupted the capacity for the emotion system to function normally, and this led excluded participants to predict a significantly less emotional response to both future positive and negative events than participants who had experienced social acceptance or control participants. This finding is potentially intriguing in that socially excluded people made affective 
forecasts that were likely more realistic than participants in the other conditions. Although their affective forecasts may have been accurate in comparison to participants in the other conditions, however, excluded participants also responded to painful stimuli in a fashion that was more characteristic of suicidal patients (Orbach et al., 1997) than people who enjoy a high degree of psychological health. The finding that increases in pain threshold and pain tolerance mediated the relationship between social exclusion and affective forecasts of emotional numbness further suggests that social exclusion caused a physically numbness to painful stimuli, which in turn led to emotional insensitivity. Future research and theory should examine the psychological benefits of overestimating the intensity and duration of emotional reactions to possible future events.

\section{Limitations and Alternative Explanations}

The five experiments reported in this paper provide consistent evidence that social exclusion produces increases in pain threshold and pain tolerance and that this physical numbness to pain accounts for the relationship between social exclusion and emotional insensitivity. Despite the consistency of these effects, however, several alternative explanations exist that warrant further consideration. A first possibility is that social exclusion simply constitutes a form of bad news. From this perspective, receiving any negatively valenced feedback should produce a temporary break down of the emotion system, resulting in numbness to painful physical stimuli. The results of our Misfortune Control condition in Experiment 2 provide evidence that is inconsistent with this perspective. Participants assigned to that condition received a negatively valenced future diagnostic forecast that was unrelated to their future belongingness status, namely that they would become accident prone later in life. Despite the relative negativity of this diagnostic forecast, Misfortune Control participants responded to painful stimuli in a manner that was most similar to participants who experienced social acceptance or who received no personality feedback.

Another possible alternative explanation for the current findings is that socially excluded participants simply responded to the pain threshold and pain tolerance measurements in a fashion that would somehow please the experimenter. Such an alternative explanation would mean that participants who experienced social exclusion felt that increasing their pain threshold and pain tolerance would lead the experimenter to think better of him or her (e.g., the participant was potentially putting more effort into the experiment than other participants). Although plausible, the results from the pain threshold measurements in Experiments 1-4 contradict such an 
alternative explanation. If socially excluded participants were trying to please the experimenter, they would have adjusted their performance in a manner that would show greater attention to the task. For example, the pain threshold measurements involved participants alerting the experimenter as to when he or she first detected the onset of pain. A socially desirable response would have therefore been a quick detection of pain, which would have demonstrated to the experimenter that the participant was paying close attention to his or her physical pain level. Socially excluded participants, in contrast, responded significantly more slowly in their reports of the onset of pain compared to participants in the other three experimental groups. Such passive responding would communicate to the experimenter that the participant might not care much about the research project, which would detract from any positive impression the socially excluded participant was trying to make on the experimenter. To be sure, socially excluded participants may have been trying to show the experimenter that they were paying close attention to the task. The findings from Experiments 1-4 suggest, however, that social exclusion disrupted participants' ability to respond to their own reactions to painful stimuli.

Another explanation is that increased pain tolerance and pain threshold among socially excluded participants are due to increased self-regulation instead of a temporary breakdown in the emotion system. To be sure, pain tolerance is often used as a measure of self-regulation (Hilgard, Ruch, Lange, Lenox, Morgan, \& Sachs, 1974) and participants may have responded to social exclusion with increased self-regulation as a means of improving their moods. The results of Experiments 1-5 showed that socially excluded participants did not report moods that were significantly different from socially accepted or control participants, which casts doubt on the likelihood that excluded participants were trying to improve their moods. The present data cannot easily rule out the idea that reduced sensitivity and increased tolerance to pain reflects increased self-regulation in response to social exclusion. Past work has clearly shown the opposite pattern, however, namely that social exclusion leads to poor self-regulation (Baumeister et al., in press; DeWall et al., 2004). If the current results could be explained in terms of effective self-regulation, excluded participants would have also probably shown high levels of empathy toward others' suffering. This was, however, not the case.

A final alternative explanation is that social exclusion produces an inability to respond to one's own emotions and the emotions of others, but that this deficit in emotional responsiveness is limited to situations involving social exclusion. The results of Experiment 5 disagree with this 
alternative explanation. The results from that study showed that rejected participants empathized less with a fellow student who had experienced physical pain and emotional discomfort due to a broken leg, but who had not experienced any threat to his or her belongingness. If social exclusion led people to empathize less only with other people who had also experienced exclusion, rejected participants in Experiment 5 would have responded in a similar manner as socially accepted and control participants. This was, however, not the case.

\section{Concluding Remarks}

The purpose of the current investigation was to resolve the seeming paradox that people respond to social exclusion with emotional numbness. Previous theoretical work has suggested that the need to belong is a fundamental and pervasive human motivation (Baumeister \& Leary, 1995), and other experimental research has shown that the behavioral consequences of social exclusion are often quite large (Buckley et al., 2004; Baumeister et al., 2002, in press; Twenge et al., 2001, 2002, 2003). It was therefore a mystery as to what processes might play a role in shaping such disordered emotional responding to social exclusion.

The current investigation may provide a first step in illuminating the reasons that socially excluded people report relatively numb emotional states. Across five experiments, we found that social exclusion causes numbness to physical pain, which in turn led to relative emotional numbness. Physical numbness to increased pain threshold and pain tolerance among socially excluded participants, which led to affective forecasts of emotional numbness and decreased empathy toward others' suffering. These results suggest that the mechanism by which socially excluded people become emotionally numb is a general shut down of the emotion system to current and possible future events.

The broader implication of the current investigation is that increased pain threshold and pain tolerance in humans may be related to the sense of belongingness a person has in his or her life. Previous work has shown that suicidal individuals, who typically have a low sense of belongingness (Joiner, in press), show similar patterns of increased pain threshold and pain tolerance as the socially excluded participants in the current experiments (Orbach et al., 1996, 1997). Other studies in the animal literature have shown that a variety of animals respond to social isolation with decreased sensitivity to physical pain (Kehoe \& Blass, 1986; Naranjo \& Fuentes, 1985; Rushen, Boissy, Terlouw, \& de Passillé, 1999; Spear, Enters, Aswad, \& Louzan, 1985; Sufka \& Hughes, 1990; Sufka \& Weed, 1994; see MacDonald \& Leary, 2005, for a 
review). It is therefore possible that one root cause of numbness to physical pain is that the individual organism perceives a threat to his or her need to belong. As a result, the individual responds to painful stimuli in a manner that is uncharacteristic of typical group members and then displays various signs of emotional insensitivity. Our results suggest that this shutdown of the emotion system has consequences for predictions of emotional responses to possible future events and empathy toward people who have experienced social exclusion and physical pain. The initial response of physical and emotional numbness to social exclusion may be beneficial in terms of providing excluded people with a means of escaping an aversive emotional state. Such responding may, however, have detrimental effects on physical and psychological well-being and preclude the possibility of regaining future social acceptance.

Our results provide consistent and conclusive evidence that social exclusion produces decreased sensitivity and increased tolerance to physical pain, which in turn led to emotional numbness. These results also lend support to the notion that promoting a more inclusive society may have beneficial effects for individual functioning and general well-being. Increasing a sense of belongingness may reduce disordered emotional responding among socially excluded people and, instead, promote responsiveness to one's self and others. This may increase a person's chances for gaining future acceptance and lead to greater physical and emotional well-being. 
Table 1. Pain threshold and pain tolerance, Experiments 1-4

\begin{tabular}{|c|c|c|c|c|}
\hline Experiment, Measure & Future Alone $\mathrm{F}$ & Future Belong & $\begin{array}{l}\text { Misfortune } \\
\text { Control }\end{array}$ & $\begin{array}{l}\text { Other } \\
\text { Control }\end{array}$ \\
\hline 1: Pain threshold & $31.73(12.46)$ & $13.27(12.68)$ & -- & $19.01(12.17)$ \\
\hline 1: Pain tolerance & $199.99(50.23)$ & $129.40(49.65)$ & 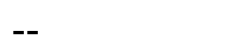 & $133.20(49.88)$ \\
\hline 2: Pain threshold & $45.94(32.05)$ & $10.55(31.46)$ & $14.41(31.89)$ & ) -- \\
\hline 2: Pain tolerance & $388.22(113.44)$ & $276.32(107.68)$ & $271.94(114.8$ & 82) -- \\
\hline 3: Pain threshold & $74.57(61.92)$ & $19.17(61.81)$ & -- & $12.52(61.87)$ \\
\hline 3: Pain tolerance & 392.53 (134.59) & $197.66(136.34)$ & -- & $216.58(133.93)$ \\
\hline 4: Pain threshold & $62.51(22.11)$ & $14.35(21.05)$ & -- & $10.24(22.22)$ \\
\hline 4: Pain tolerance & $496.84(120.97)$ & $236.05(120.81)$ & -- & $244.47(109.89)$ \\
\hline
\end{tabular}

Note. Values represent mean pain threshold and pain tolerance scores. In all experiments, baseline pain threshold and pain tolerance scores were entered as covariates. Standard deviations appear in parentheses. 


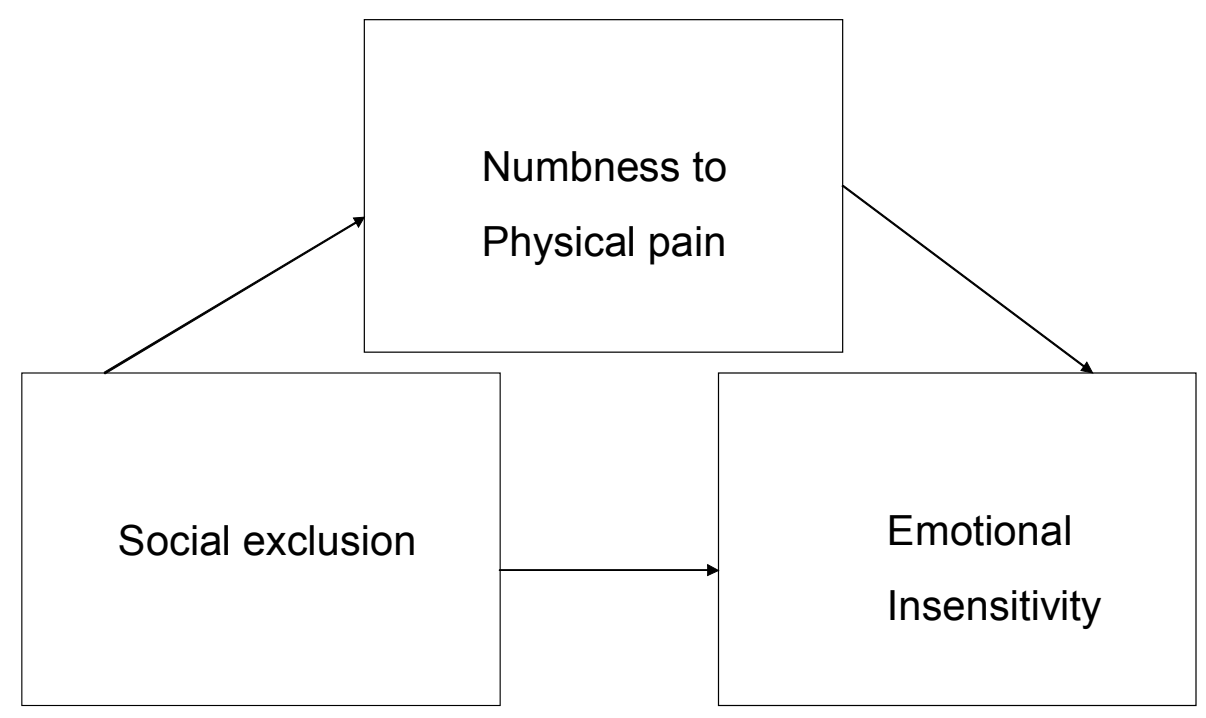

Figure 1. Proposed mediational model of social exclusion, numbness to physical pain, and emotional insensitivity.

Note. A hypothesized mediational model representing a sequential process beginning with social exclusion, then numbness to physical pain, and finally emotional insensitivity. 


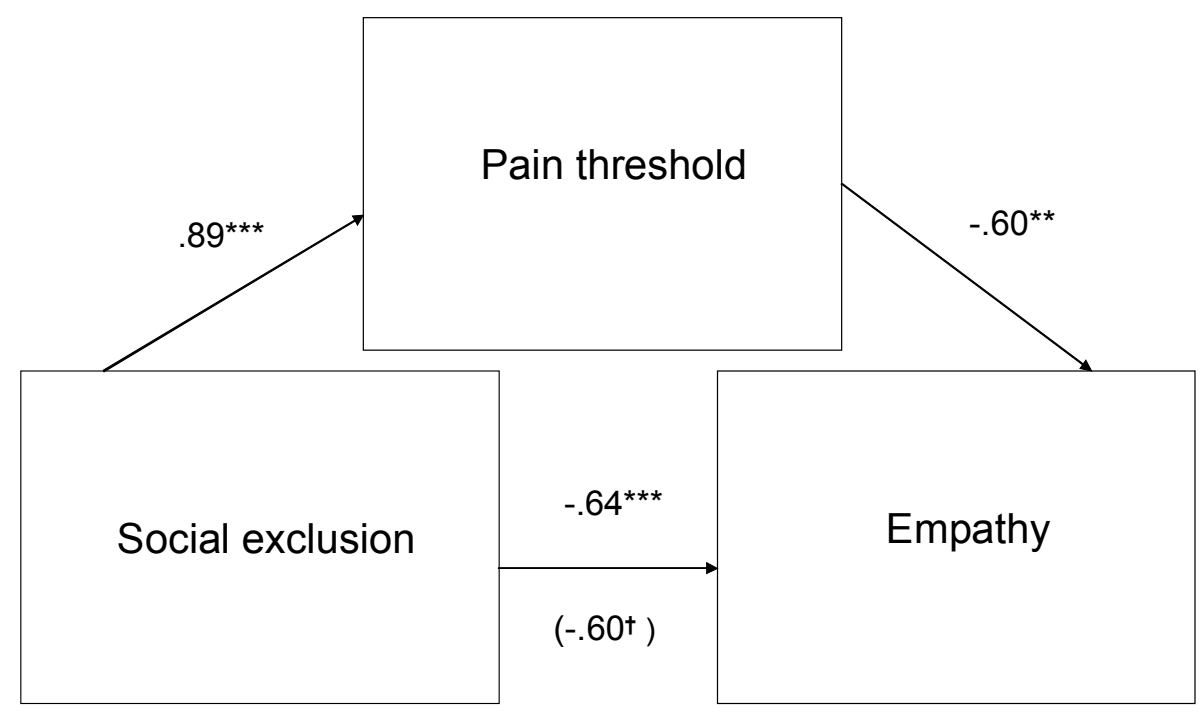

Figure 2. Mediational effect of increased pain threshold on social exclusion and decreased empathy. Experiment 4.

Note. "Social exclusion" refers to the personality feedback condition to which participants were assigned. Conditions were coded such that $1=$ Future Alone and $0=$ Future Belonging and No feedback control. "Pain threshold" signifies participants' mean pain threshold score after covarying baseline pain threshold scores. "Empathy" stands for mean scores on the empathy index.

Values represent the standardized regression coefficient $(\beta)$, which corresponds to the effect of the predictor variable on the dependent variable (e.g., social exclusion condition $\rightarrow$ expressed empathy). All models used baseline pain threshold scores as a covariate.

$* * * p<.001 . \dagger p=.07$ 


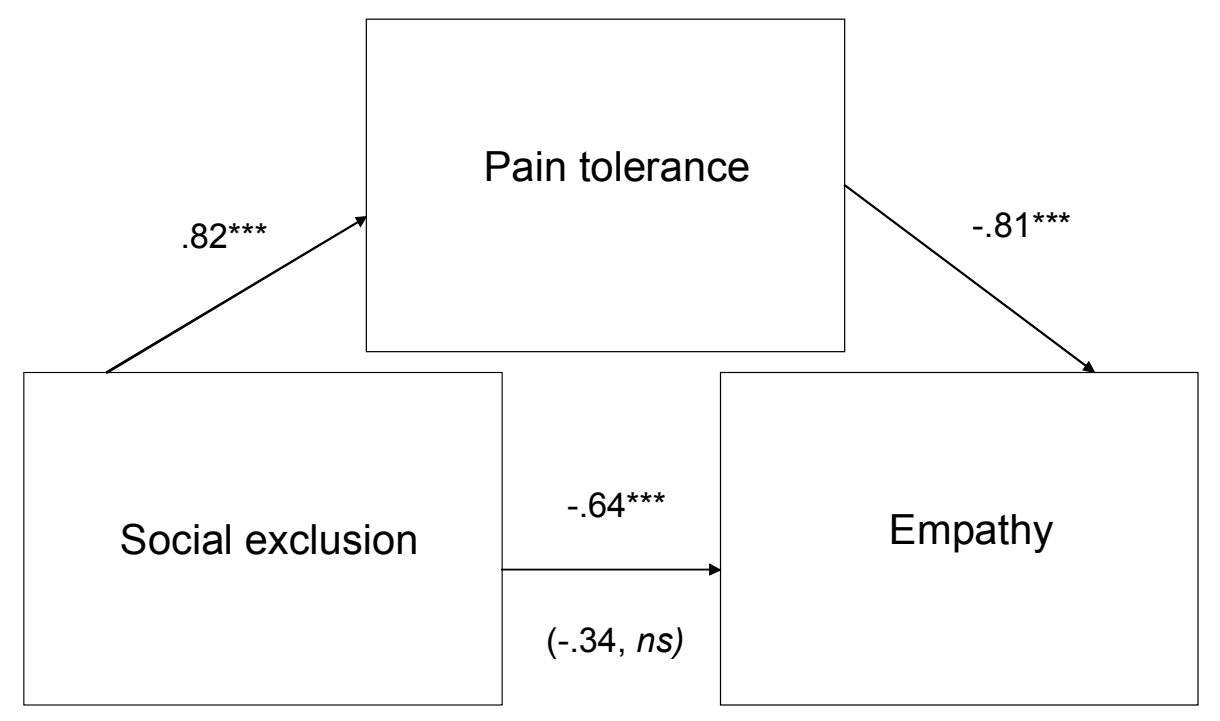

Figure 3. Mediational effect of increased pain tolerance on social exclusion and decreased empathy. Experiment 4.

Note. "Social exclusion" refers to the personality feedback condition to which participants were assigned. Conditions were coded such that $1=$ Future Alone and $0=$ Future Belonging and No feedback control. "Pain tolerance" signifies participants' mean pain tolerance score after covarying baseline pain tolerance scores. "Empathy" stands for mean scores on the empathy index.

Values represent the standardized regression coefficient $(\beta)$, which corresponds to the effect of the predictor variable on the dependent variable (e.g., social exclusion condition $\rightarrow$ expressed empathy). All models used baseline pain tolerance scores as a covariate.

$$
* * * p<.001
$$




\section{APPENDIX}

\section{(10) \\ Min. \\ Forida State}

Office of the Vice President For Research

Human Subjects Committee

Tallahassee, Florida 32306-2763

(850) 644-8633 - FAX (850) 644-4392

\section{APPROVAL MEMORANDUM}

Date: $8 / 5 / 2004$

To:

Nathan DeWall

MC 1270

\section{Dept.: PSYCHOLOGY DEPARTMENT}

From: John Tomkowiak, Chair Personality and physical sensitivity

The forms that you submitted to this office in regard to the use of human subjects in the proposal referenced above have been reviewed by the Human Subjects Committee at its meeting on 7/21/2004. Your project was approved by the Committee.

The Human Subjects Committee has not evaluated your proposal for scientific merit, except to weigh the risk to the human participants and the aspects of the proposal related to potential risk and benefit. This approval does not replace any departmental or other approvals which may be required.

If the project has not been completed by $7 / 20 / 2005$ you must request renewed approval for continuation of the project.

You are advised that any change in protocol in this project must be approved by resubmission of the project to the Committee for approval. Also, the principal investigator must promptly report, in writing, any unexpected problems causing risks to research subjects or others.

By copy of this memorandum, the chairman of your department and/or your major professor is reminded that he/she is responsible for being informed concerning research projects involving human subjects in the department, and should review protocols of such investigations as often as needed to insure that the project is being conducted in compliance with our institution and with DHHS regulations.

This institution has an Assurance on file with the Office for Protection from Research Risks. The Assurance Number is IRB00000446.

cc: Roy Baumeister

HSC No. 2004.457 


\section{INFORMED CONSENT FORM}

\section{Personality and physical sensitivity}

I freely and voluntarily and without element of force or coercion, consent to be a participant in the research project entitled "Personality and sensitivity." This research is being conducted by C. Nathan DeWall, a graduate student in the Department of Psychology at Florida State University working under the supervision of Dr. Roy Baumeister, professor of psychology in the Department of Psychology at Florida State University. I understand the purpose of their research project is to better understand how personality, verbal and nonverbal behaviors, and their relation to physical sensitivity. I understand to participate in this project I must be right-handed, a non-smoker, and have not have ingested any sugared or alcoholic beverage for at least one hour prior to my participation. I have also not have taken any analgesics (e.g., aspirin, acetaminophen) or other pain suppressants (e.g., oxycodone with acetaminophen (Percocet) or propoxyphene with acetaminophen (Darvocet) for at least 8 hours prior to participation in the experiment In addition, I understand that the experiment may involve exposure to activities that may be physically uncomfortable, although any discomfort I may experience will be mild and short-lived. I will also be asked to complete several questionnaires aimed at better understanding my personality. The total time commitment would be about an hour, and I will be compensated by receiving a credit point for my time.

I understand that I must be 18 years of age to participate. I understand that my participation is totally voluntary and I may stop participation at anytime. If I decide to stop participation, I will still be entitled to the compensation. All my responses to the tasks will be anonymous and will not be tied back to me personally. My name will not appear on any of the results. No individual responses will be reported in any publication. Only group findings will be reported. The all data, identified only by subject code number, will be stored in a locked file cabinet and will be destroyed by August 31,2008. My participation in this project will remain confidential to the extent allowed by law.

I understand there is a possibility of a minimal level of risk involved if I agree to participate in this study. I might experience anxiety or frustration when completing the tasks. I may also experience slight physical discomfort when completing the tasks. The research assistant will be available to talk with me about any emotional discomfort I may experience while participating. I am also able to stop my participation at any time I wish.

I understand that this consent may be withdrawn at any time without prejudice, penalty, or loss of benefits to which I am otherwise entitled. I have been given the right to ask and have answered any inquiry concerning the study. Questions, if any, have been answered to my satisfaction.

I understand that I may contact C. Nathan DeWall, Florida State University, Department of Psychology, Psychology building room 112, 645 - 1498, or Dr. Roy Baumeister, Department of Psychology, Psychology building room 323a, $645-1409$, for answers to questions about this research or my rights. Group results will be sent to me upon my request. If I have questions about my rights as a subject/participant in this research, or if I feel I have been placed at risk, I can contact the Chair of the Human Subjects Committee, Institutional Review Board, through the Office of the Vice President for Research, at (850) 644-8633.

I have read and understand this consent form.

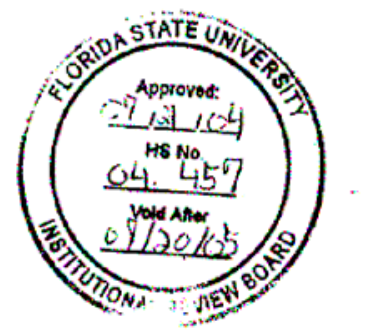




\section{REFERENCES}

Baron, R. M., \& Kenny, D. A. (1986). The moderator-mediator variable distinction in social psychological research: Conceptual, strategic, and statistical considerations. Journal of Personality and Social Psychology, 51, 1173-1182.

Batson, C. D., Klein, T. R., Highberger, L., \& Shaw, L. L. (1995). Immorality from empathyinduced altruism: When compassion and justice conflict. Journal of Personality \& Social Psychology, 68, 1042-1054.

Batson, C. D. (1987). Prosocial motivation: Is it ever truly altruistic? In L. Berkowitz (Ed.), Advances in experimental social psychology (Vol. 20, pp. 65-122). New York: Academic.

Batson, C. D. (1991). The altruism question: Toward a social-psychological answer. Hillsdale, NJ: Erlbaum.

Baumeister, R. F. (1990). Suicide as escape from the self. Psychological Review, 97, 90-113.

Baumeister, R. F. \& Leary, M. R. (1995). The need to belong: Desire for interpersonal attachments as a fundamental human motivation. Psychological Bulletin, 117, 497-529.

Baumeister, R. F., Twenge, J. M., \& Nuss, C. K. (2002). Effects of social exclusion on cognitive processes: Anticipated aloneness reduces intelligent thought. Journal of Personality and Social Psychology, 83, $817-827$.

Buckley, K. E., Winkel, R. E., \& Leary, M. R. (2004). Reactions to acceptance and rejection: Effects of level and sequence of relational evaluation. Journal of Experimental Social Psychology, 40, 14-28.

Bush, G., Luu, P. \& Posner, M. I. (2000). Cognitive and emotional influences in anterior cingulate cortex. Trends Cog. Sci. 4, 215-222.

Cacioppo, J. T., Hawkley, L. C., \& Berntson, G. G. (2003). The anatomy of loneliness. Current Directions in Psychological Science, 12, 71-74.

Carden, S. E., Hernandez, N. \& Hofer, M. A. (1996). The isolation and companion comfort responses of 7- and 3-day-old rat pups are modulated by drugs active at the opioid receptor. Behavioral Neuroscience, 110, $324-330$.

Carden, S. E. \& Hofer, M. A. (1990). Socially mediated reduction of isolation distress in rat pups is blocked by naltrexone but not by Ro 15-1788. Behavioral Neuroscience, 104, $457-463$.

Craig, A. D. \& Dostrovsky, J. O. (1999). Medulla to thalamus. In P. Wall \& R. Melzack (Eds.) Textbook of pain $(183-214)$. New York: Churchill Livingstone. 
DeWall, C. N., Baumeister, R. F., \& Vohs, K. D. (2004). Recovering from rejection: Undoing the self-regulation deficits stemming from social exclusion. Manuscript submitted for publication.

Downey, G., \& Feldman, S. I. (1996). Implications for rejection sensitivity for intimate relationships. Journal of Personality and Social Psychology, 70, 1327-1343.

Eisenberger, N. I., \& Lieberman, M. D. (2004). Why rejection hurts: The neurocognitive overlap between physical and social pain. Trends in Cognitive Sciences, 8, 294-300.

Eisenberger, N. I., Lieberman, M. D., \& Williams, K. D. (2003). Does rejection hurt? An fMRI study of social exclusion. Science, 302, 290-292.

Eysenck, H. J., Eysenck, S. B. G. (1975). Manual of the Eysenck Personality Questionnaire. San Diego, CA: EDITS.

Gardner, W. L., Pickett, C. L., \& Brewer, M. B. (2000). Social exclusion and selective memory: How the need to belong influences memory for social events. Personality and Social Psychology Bulletin, 26, 486-496.

Gilbert, D. T., Gill, M. J., \& Wilson, T. D. (2002). The future is now: Temporal correction in affective forecasting. Organization Behavior and Human Decision Processes, 88, 430444.

Gilbert, D. T., Pinel, E. C., Wilson, T. D., Blumberg, S. J., \& Wheatley, T. (1998). Immune neglect: A source of durability bias in affective forecasting. Journal of Personality and Social Psychology, 75, 617-638.

Hariri, A. R., Bookheimer, S. Y., \& Mazziotta, J. C. (2000). Modulating emotional responses: Effects of a neocortical network on the limbic system. Neuroreport, 11, 43-48.

Hawkley, L. C., Burleson, M. H., Berntson, G. G., \& Cacioppo, J. T. (2003). Loneliness in everyday life: Cardiovascular activity, psychosocial context, and health behaviors. Journal of Personality \& Social Psychology, 85, 105-120.

Hilgard, E. R., Ruch, J. C., Lange, A. F., Lenox, J. R., Morgan, A. H., \& Sachs, L. B. (1974). The psychophysics of cold pressor pain and its modification through hypnotic suggestion. American Journal of Psychology, 87, 17-31.

Hoffman, M. L. (1976). Empathy, role-taking, guilt, and development of altruistic motives. In T. Lickona (Ed.), Moral development and behavior: Theory, research, and social issues (pp. 124-143). New York: Holt, Rinehart, \& Winston.

Insel, T. R. \& Winslow, J. T. (1991). Central administration of oxytocin modulates the infant rat's response to social isolation. European Journal of Pharmacology, 203, $149-152$. 
Jepson, C., Loewenstein, G., \& Ubel, P. (2001). Actual versus estimated differences in quality of life before and after renal transplant. Unpublished manuscript, Department of Social and Decision Sciences, Carnegie Mellon University.

Joiner, T. (in press). Why people die by suicide. Cambridge, MA: Harvard University Press.

Kahneman, D., \& Tversky, A. (Eds.) (2000). Choices, values, and frames. Cambridge: Cambridge University Press.

Kanarek, R. B., \& Carrington, C. (2004). Sucrose consumption enhances the analgesic effects of cigarette smoking in male and female smokers. Psychopharmacology, 173, 57-63.

Kehoe, P. \& Blass, E. M. (1986a). Opioid-mediation of separation distress in 10-day-old rats: Reversal of stress with maternal stimuli. Developmental Psychobiology, 19, 385 - 398.

Kehoe, P., \& Blass, E. M. (1986b). Behaviorally functional opioid systems in infant rats: II. Evidence for pharmacological, physiological, and psychological mediation of pain and stress. Behavioral Neuroscience, 100, $624-630$.

Kenny, D. A., Kashy, D. A., \& Bolger, N. (1998). Data analysis in social psychology. In D. Gilbert, S. Fiske, \& G. Lindzey (Eds.), The handbook of social psychology (Vol. 1, 4th ed., pp. 233-265). Boston: McGraw-Hill.

Kimbrell, T. A., George, M. S., Parekh, P. I., Ketter, T. A., Podell, D. M., Danielson, A. L., Repella, J. D., Benson, B. E., Willis, M. W., Herscovitch, P., \& Post, R. M. (1999). Regional brain activity during transient self-induced anxiety and anger in healthy adults. Biological Psychiatry, 46, 454-465.

Konecka, A. M. \& Sroczynska, I. (1990). Stressors and pain sensitivity in CFW mice: Role of opioid peptides. Archives Internationales de Physiologie et de Biochimie, 98, 245 - 252.

Kosslyn, S. M., Pascual-Leone, A., Felician, O., Camposano, S., Keenan, J. P., Thompson, W. L., Ganis, G., Sukel, K. E., \& Alpert, N. M. (1999). The role of area 17 in visual imagery: Convergent evidence from PET and rTMS. Science, 284, 167-170.

Krebs, D. L., \& Russell, C. (1981). Role-taking and altruism: When you put yourself in the shoes of another, will they take to their owner's aid? In J. P. Rushton \& E. Aronson (Eds.), Altruism and helping behavior: Social, personality, and developmental perspectives (pp. 137-165). Hillsdale, NJ: Erlbaum.

Leary, M. R. \& Springer, C. A. (2000). Hurt feelings: The neglected emotion. In R. Kowalski (Ed.) Aversive behaviors and interpersonal transgression. Washington, DC: American Psychological Association.

Loewenstein, G., O’Donoghue, T., \& Rabin, M. (in press). Projection bias in predicting future utility. Quarterly Journal of Economics. 
MacDonald, G., Kingsbury, R., \& Shaw, S. (in press). Adding insult to injury: Social pain theory and response to social exclusion. In K. Williams, J. Forgas, \& W. von Hippel (Eds.) The social outcast: Ostracism, social exclusion, rejection, \& bullying. New York: Psychology Press.

MacDonald, G. \& Leary, M. R. (2005). Why does social exclusion hurt? The relationship between social and physical pain. Psychological Bulletin, 131, 202-223.

Mayer, J. D., \& Gaschke, Y. N. (1988). The experience and meta-experience of mood. Journal of Personality and Social Psychology, 55, 102-111.

McGuire, P. K., Shah, G. M. S., \& Murray, R. M. (1993). Increased blood flow in Broca's area during auditory hallucinations in schizophrenia. Lancet, 342, 703-706.

Mercer, M. E., \& Holder, M. D. (1997). Antinociceptive effects of palatable sweet ingesta on human responsivity to pressure pain. Physiology \& Behavior, 61, 311-318.

Murray, F. S., \& Hagan, B. C. (1973). Pain threshold and tolerance of hands and feet. Journal of Comparative \& Physiological Psychology, 84, 639-643.

Naranjo, J. R. \& Fuentes, J. A. (1985). Association between hypoalgesia and hypertension in rats after short-term isolation. Neuropharmacology, 24, $167-171$.

Nelson, E. E. \& Panksepp, J. (1998). Brain substrates of infant-mother attachment: Contributions of opioids, oxytocin, and norepinephrine. Neuroscience and Biobehavioral Reviews, 22, 437-452.

Nelson, L. D., \& Morrison, E. L. (in press). The symptoms of resource scarcity: Judgments of food and finances influence preferences for potential partners. Psychological Science.

Nisbett, R. E., \& Ross, L. D. (1980). Human inference: Strategies and shortcomings of social judgment. Englewood Cliffs, NJ: Prentice-Hall.

Orbach, I., Stein, D., Palgi, Y., Asherov, J., Har-Even, D., \& Elizur, A. (1996). Perception of physical pain in accident and suicide attempt patients: Self-preservation vs. selfdestruction. Journal of Psychiatric Research, 30, 307-320.

Orbach, I., Mikulincer, M., King, R., Cohen, D., \& Stein, D. (1997). Thresholds and tolerance of physical pain in suicidal and nonsuicidal patients. Journal of Consulting and Clinical Psychology, 65, 646-652.

Panksepp, J. (1998). Affective neuroscience: The foundations of human and animal emotions. London: Oxford University Press.

Petrovic, P., Kalso, E., Petersson, K. M., \& Ingvar, M. (2002). Placebo and opioid analgesiaimaging a shared neural network. Neuroimage, 16, 1142-1150. 
Pomerleau, O. F., Turk, D. C., \& Fertig, J. B. (1984). The effects of cigarette smoking on pain and anxiety. Addictive Behaviors, 9, 265-271.

Rossi, G. C., Pasternak, G. W., \& Bodnar, R. J. (1993). Synergistic brainstem interactions for morphine analgesia. Brain Research, 624, 171-180, 1993.

Rosenberg, M. (1965). The measurement of self-esteem: Society and the adolescent self-image. Princeton: Princeton.

Rushen, J., Boissy, A., Terlouw, E. M., \& de Passillé, A. M. (1999). Opioid peptides and behavioral and physiological responses of dairy cows to social isolation in unfamiliar surroundings. Journal of Animal Science, 77, 2918 - 2924.

Sobel, M. E. (1982). Asymptotic confidence intervals for indirect effects in structural equation models. In S. Leinhardt (Ed.), Sociological Methodology 1982 (pp. 290-312).

Washington DC: American Sociological Association.

Spear, L. P., Enters, E. K., Aswad, M. A., \& Louzan, M. (1985). Drug and environmentally induced manipulations of the opiate and serotonergic systems alter nociception in neonatal rat pups. Behavioral and Neural Biology, 44, 1 - 22.

Stotland, E. (1969). Exploratory studies of empathy. In L. Berkowitz (Ed.), Advances in experimental social psychology (Vol. 4, pp. 271-313). New York: Academic.

Sufka, K. J. \& Hughes, R. A. (1990). Dose and temporal parameters of morphine-induced hyperalgesia in domestic fowl. Physiology and Behavior, 47, 385-387.

Sufka, K. J. \& Weed, N. C. (1994). Construct validation of behavioral indices of isolation stress and inflammatory nociception in young domestic fowl. Physiology and Behavior, 55, 741 - 746.

Twenge, J. M., Baumeister, R. F., Tice, D. M., \& Stucke, T. S. (2001). If you can't join them, beat them: Effects of social exclusion on aggressive behavior. Journal of Personality and Social Psychology, 81, 1058 - 1069.

Twenge, J.M., Catanese, K. R., \& Baumeister, R.F. (2003). Social exclusion and the deconstructed state: Time perception, meaninglessness, lethargy, lack of emotion, and self-awareness. Journal of Personality and Social Psychology, 85, 409-423.

Twenge, J.M., Catanese, K. R., \& Baumeister, R.F. (2002). Social exclusion causes selfdefeating behavior. Journal of Personality and Social Psychology, 83, 606-615.

Uchino, B. N., Cacioppo, J. T., \& Kiecolt-Glaser, J. K. (1996). The relationship between social support and physiological processes: A review with emphasis on underlying mechanisms and implications for health. Psychological Bulletin, 119, 488-531. 
Van Boven, L., \& Loewenstein, G. (2003). Social projection of transient drive states. Personality and Social Psychology Bulletin, 29, 1159-1168.

Wiedenmayer, C. P., Goodwin, G. A., \& Barr, G. A. (2000). The effect of periaqueductal gray lesions on responses to age-specific threats in infant rats. Developmental Brain Research, 120, 191 - 198.

Williams, K. D. (2001). Ostracism: The power of silence. New York: Guilford Press.

Williams, K. D., Cheung, C. K. T., \& Choi, W. (2000). CyberOstracism: Effects of being ignored over the Internet. Journal of Personality and Social Psychology, 79, 748-762.

Wilson, T. D., \& Gilbert, D. T. (2003). Affective forecasting. In M. P. Zanna (Ed.), Advances in experimental social psychology (Vol. 35, pp. 345-411). San Diego: Academic Press.

Wilson, T. D., \& LaFleur, S. J. (1995). Knowing what you'll do: Effects of analyzing reasons on self-prediction. Journal of Personality and Social Psychology, 68, 21-35.

Wilson, T. D., Wheatley, T., Kurtz, J., Dunn, E., \& Gilbert, D. T. (2004). When to fire: Anticipatory versus post-event reconstrual of uncontrollable events. Personality and Social Psychology Bulletin, 30, 340-351.

Wilson, T. D., Wheatley, T., Meyers, J. M., Gilbert, D. T., Axsom, D. (2000). Focalism: A source of durability bias in affective forecasting. Journal of Personality and Social Psychology, 78, 821-836.

Zadro, L., Williams, K. D., \& Richardson, R. (2004). How low can you go? Ostracism by a computer is sufficient to lower self-reported levels of belonging, control, self-esteem, and meaningful existence. Journal of Experimental Social Psychology, 40, 560-567. 


\section{BIOGRAPHICAL SKETCH}

C. Nathan DeWall was born in Watertown, South Dakota. He received his B. A. in Psychology from St. Olaf College and an M. A. in Social Sciences from the University of Chicago. He has published articles and chapters on topics ranging from gender stereotyping, sexuality, social exclusion and rejection, consciousness and free will, aggression, self-control, and evolutionary psychology. He plans on completing his Ph.D. in social psychology at Florida State University, after which time he hopes to obtain a professorship at a research-one university. 